ANUARIo DE Estudios Medievales (AEM)

37/1, enero-junio de 2007

pp. 267-304

ISSN 0066-5061

\title{
EL LIBRO DE LA GUERRA, Y LA TRADUCCIÓN DE VEGECIO POR FRAY ALFONSO DE SAN CRISTÓBAL
}

\author{
THE "LIBRO DE LA GUERRA", \\ AND VEGECIO'S TRANSLATION \\ BY FRAY ALFONSO DE SAN CRISTÓBAL
}

MARÍA ElVIRA ROCA BAREA

I.E.S. Alfaguara, Yunquera (Málaga)

Resumen: Este trabajo se ocupa del breve y anónimo tratado conocido como Libro de la guerra que Lucas de Torre editó en 1916. Su origen ha sido un misterio hasta ahora, pero en realidad este texto no es más que un resumen de la traducción al castellano del Epitome rei militaris que fray Alfonso de San Cristóbal hizo para Enrique III. Descubrí una copia desconocida y no catalogada del Libro de la guerra en el manuscrito 9806 (Madrid, Biblioteca Nacional), el cual perteneció a la biblioteca del Conde de Haro, que me ha ayudado a llevar a cabo una nueva y más completa edición del Libro de la guerra y a establecer algunos datos importantes sobre este texto. La última parte del artículo está dedicada a precisar algunos aspectos de la influencia de Vegecio en la Castilla tardomedieval.

Palabras clave: Libro de la guerra. Vegecio. Castilla. Traducción.

\begin{abstract}
This article is devoted to the brief and anonymous military treatise socalled Libro de la guerra that was edited in 1916 by Lucas de Torre. Its origin was a mystery until now, but this text is only a resume of a Spanish translation of Vegetius' Epitome rei militaris that brother Alfonso de San Cristobal did for Enrique III of Castile. I discovered a unknown and never catalogued copy of the Libro de la guerra in the manuscript 9806 (Madrid, Biblioteca Nacional) that belonged to the library of the Conde de Haro that help me to do a new and more complete edition and to establish some important data about the Libro de la guerra. The last part of my work is devoted to the knowledge and influence of Vegetius at the end of the Middle Age in Castile.
\end{abstract}

Keywords: Libro de la guerra. Vegetius. Castile. Translation.

En 1916 Lucas de Torre editó un pequeño tratado militar, el Libro de la guerra, presuntamente salido de la pluma de Enrique de Villena, aunque el propio autor de la edición expresaba sus dudas sobre la autoría. La introducción de Lucas de Torre, de apenas 30 líneas, insiste sin embargo en que, aunque el tratado no fuese de don Enrique "no por eso pierde su importancia, pues, perdidas las obras militares del infante don Juan Manuel, queda esta que nos ocupa como la primera obra militar escrita en español, ya que, por el carácter de letra y demás circunstancias que en ella concurren, ha tenido que 
ser escrita en la primera mitad del siglo XV"1. Las esperanzas del editor resultaron ser excesivas. Primeramente Derek C. Carr demostró que Villena no era el autor ${ }^{2}$. La confusión se debió al hecho de que el opúsculo militar compartía el códice con la copia de los Doze trabajos de Hercules. A este códice (Biblioteca Nacional, ms. 6526) le fue cambiada la portada en el siglo XVIII por otra llena de errores, entre ellos el que comentamos. En segundo lugar, debemos ahora señalar que, en realidad, el Libro de la guerra es un resumen de la traducción que fray Alfonso de San Cristóbal hizo del Epitome rei militaris de Vegecio, probablemente para Enrique III, por lo que tampoco se la puede considerar como "la primera obra militar escrita en español".

Hasta donde sabemos, el primer romanceamiento que se hizo en Castilla de la obra de Vegecio se debió al dominico Alfonso de San Cristóbal. Desdichadamente fray Alfonso no es más que un nombre para nosotros. Amador de los Ríos escribe que esta traducción le fue dedicada a Enrique IV (1425-1474) en cuya corte, afirma, fue celebrado como orador excelente el traductor, aunque no cita la fuente de donde obtiene esta información. La Biblioteca Hispana Antigua remite también a Enrique $\mathrm{IV}^{3}$, el cual reinó desde 1454 a 1474. Rodríguez Velasco considera improbable que el eclesiástico tradujera para este rey. En los manuscritos se lee solamente que dedica su trabajo al muy alto $\tau$ muy claro prinçipe poderoso don Enrrique por la graçia de Dios rey (Biblioteca Menéndez Pelayo de Santander, ms.

94, fol. 1r) ${ }^{4}$. De fray Alfonso sabemos positivamente sólo lo que él dice de sí mismo: afirma pertenecer a la ordo predicatorum y que es orador del rey, o sea, que ocupa un cargo en la capellanía real, encargada de hacer los sermones que el rey oía ${ }^{5}$. Hubo muchos franciscanos y dominicos entre los

${ }^{1}$ Lucas de TORRE, ed. El libro de la guerra "Revue Hispanique”, 38 (1916), pp. 497-531. De Torre sigue el manuscrito 6526 (fol. $61 \mathrm{v}-85 \mathrm{v}$ ) de la Biblioteca Nacional de Madrid en esta edición.

${ }^{2}$ Enrique de VILlena, Enrique de Villena, Tratado de la Consolación, ed. D.C. Carr, Madrid, 1977, p. 1v.

${ }^{3}$ Nicolás Antonio, Biblioteca Hispana Antigua, ed. Francisco Pérez Bayer y director de la traducción Gregorio de Andrés Martínez, 1998, vol. II, p. 241 (es traducción de la edición que hizo don Francisco Pérez Bayer en 1788). En la nota 3 se dice: "Autores que se han de añadir desde el año MCCCCXL y hasta el año MCCCCL. Alfonso de San Cristóbal, dominico, ignorado por cierto por Quertif y Echard, bibliógrafos de su misma orden, es el autor de la Hispanica versio literalis, moralis et ascetica IV librorum Flavii Vegetii De re militari, in tres partes divisae. Se conserva en el códice L. I. 10 de la Biblioteca del Escorial (Tom. III, p. 225) y en el Diagram Plut II. 18 (Tom. II, p. 218). Está dedicado al rey Juan II y al parecer también a Enrique IV de Castilla. Contiene comentarios y alegorías con las que el hombre interior se puede defender contra las emboscadas del espíritu. La primera de las tres partes en que está dividida Dira lo que dixo Vegecio en sus libros rromacandandolo. En la segunda Sera como glossa de los libros de los Sabios que concuerdan con Vegecio. En la tercera Fablara espiritualmente, trayendo los dichos de Vegecio a las veces a las virtudes e a los pecados de esta vida".

${ }^{4}$ Todas las transcripciones las he hecho a partir de este códice. No es, como se verá a continuación, el único que ha conservado la traducción glosada de fray Alfonso, pero sí es
probablemente el mejor conservado.

${ }^{5}$ frey Alfonso de Sant Xristoual, maestro en sancta theologia, vuestro seruidor $\tau$ uuestro orador äeuoto (fol. 1r). Explicit: Este libro rromanco frey Alfonso de Sant Xristoual, maestro en theologia de la orden de los predicadores $\tau$ lo gloso $\tau$ declaro en algunos logares segund paresce por el por mandado del muy alto prinçipe $\tau$ señor rrey de Castilla $\tau$ de Leon don Enrrique, por la graçia de Dios, a quien Dios de santo paraiso $\tau$ gloria perdurable. Amen (fol. $93 \mathrm{r}$, ms. 94, Biblioteca Menéndez Pelayo, Santander). 
confesores reales de Juan I y hasta Juan II. Sabemos de la existencia de un fray Alfonso de Cusanza (m. 1437), dominico, que fue confesor de Enrique III y luego de Juan II. Este era un puesto importante, tanto desde el punto de vista político como religioso, pero no hay prueba que permita identificar ambos personajes a pesar de las coincidencias: los dos son teólogos, alfonsos, maestros en teología con un oficio real... Así lo reconoce Rodríguez Velasco que, en cambio, sí considera que fue en la época en que Alfonso de Cusanza fue confesor de Enrique III cuando se tradujo y glosó el libro de Vegecio, ya que los confesores conocidos de Enrique IV son franciscanos o jerónimos, y es lógico suponer que llenaran la capellanía regia de los hombres de su orden. En cambio en la corte de Enrique III predominan los predicadores. Por lo tanto, la afirmación de Amador de los Ríos se ha de desestimar ${ }^{6}$.

La traducción del Epitome se hace por petición del rey, según fray Alfonso hace constar: señor, por quanto fue la vuestra merçed de me mandar romançar en nuestro lenguaje el libro $\tau$ la obra que fizo Vegecio dela caualleria $\tau$ dela arte delas batallas (fol. 1v). Parece que Vegecio gozó de gran predicamento entre los monarcas desde los tiempos de Alfonso X. Luego, de la traducción de fray Alfonso, tuvo una copia Isabel I de Castilla, que poseyó además otra en latín ${ }^{7}$.

En cualquier caso, dejando en suspenso la identificación de ambos Alfonsos, la traducción del dominico fue anterior a 1455, porque en esa fecha el resumen de su traducción conocido como Libro de la guerra es incorporado a la biblioteca con que don Pedro Fernández de Velasco dotó al Hospital de la Veracruz. Es en este momento cuando el manuscrito 9608 (Biblioteca Nacional) que contiene un ejemplar no localizado hasta ahora del Libro de la guerra, fue donado al Hospital, en Medina de Pomar. Creemos que este es el manuscrito que se encontraba en dicha biblioteca, y no el manuscrito 9253 (Biblioteca Nacional), como afirma Lawrence ${ }^{8}$, por los motivos que a continuación explicamos.

De la biblioteca del conde de Haro conservamos dos inventarios. Uno se hizo cuando la biblioteca se creó, en 1455, y otro fue mandado confeccionar por un descendiente del primer conde en 1553. Si consultamos la copia dieciochesca del catálogo de la biblioteca del conde de Haro (Biblioteca Nacional, ms. res. 141), encontramos que en él se consigna, en el inventario de 1553, un códice del que se dice: Julio Frontino que trata de diversas mañas y exemplos para el Capitan sobre lo que ha de hacer antes de entrar en la batalla en el primero libro. Y en el Segundo de las cosas que se han de hacer en la Batalla; $Y$ en el tercero de como se han de combatir las ciudades. En el quarto de las cosas que son semejantes a la distincion de los primeros

${ }^{6}$ José AMADOR DE LOS Ríos, Historia Crítica de la literatura española, Madrid, 1969, vol. VI p. 324 . Es edición facsímil de la primera impresa en 1865 . Jesús D. RODRÍGUEZ VELASCO, $E l$ debate sobre la caballería en el siglo XV, Salamanca, 1996, pp. 38-39.

${ }^{7}$ Francisco J. SÁNCHEZ CANTÓN, Libros, tapices y cuadros que coleccionó Isabel la Católica, Madrid, 1950, p. 71.

${ }^{8} \mathrm{~J}$ eremy N. H. LAWRENCE, Nueva luz sobre la biblioteca del Conde de Haro: inventario de 1455, "El Crotalón", 1 (1984) p. 1083. 
echos. Y despues trata por treinta y seis reglas de las batallas y al fin, escrive una carta de loas de los capitanes de la guerra, todo escrito de mano en Romance (fol.12v). El códice ya se halla en el inventario de 1455 como asiento LII ${ }^{9}$. Esas 36 reglas aparecen al final del manuscrito 9608 (fols. 63v$77 \mathrm{v}$ ). Ellas son una copia hasta el momento no conocida del Libro de la guerra que erróneamente se atribuyera a Enrique de Villena. La presencia de estas 36 reglas de la milicia prueban de manera definitiva que el manuscrito 9608 es el que perteneció al conde de Haro. Lawrence ha identificado sin acierto el ejemplar mencionado en los dos catálogos de la biblioteca de Medina de Pomar con el manuscrito 9253, probablemente porque este es también una traducción de Frontino. No sabemos cómo llegaron el romanceamiento de Frontino y el resumen de la traducción de Vegecio que llamamos Libro de la guerra a manos de don Pedro Fernández de Velasco, y si fue él quien lo mandó hacer, o quién fue su autor ${ }^{10}$.

Este dato parece corroborar a Enrique III como dedicatario de la traducción de Vegecio, porque si Enrique IV subió al trono en 1454 y encargó la traducción de Vegecio después, parece un poco precipitado que ya estuviera concluida al año siguiente. En tal caso la versión se hizo entre 1390, fecha en que el Doliente subió al trono, y 1406, año de su muerte.

El éxito de Vegecio en la Castilla medieval es bastante importante y muy superior a otros autores de re militari, como Frontino, por ejemplo. Vegecio, autor cristiano que vivió probablemente en el siglo $\mathrm{V}$, bajo Teodosio, fue una de las auctoritates favoritas de la Edad Media, la principal indiscutiblemente sobre milicia ${ }^{11}$. Sólo Plinio el Viejo y su Naturalis Historia rivalizan con el número de copias de Vegecio que existen en las bibliotecas europeas antes de 1300. Schrader proporciona una lista muy completa de los manuscritos latinos y traducciones de Vegecio a distintas lenguas ${ }^{12}$. Cataloga entre los siglos IX-XV nada menos que 243 códices latinos, 46 de distintas

${ }^{9}$ LAWRENCE, Nueva luz, pp. 1072-1111. Antonio PAZ y MELIÁ, Biblioteca fundada por el conde de Haro en 1455, "Revista de Archivos, Bibliotecas y Museos" (3a epoca), I (1897), pp. 18-24, 60-66, 156-163, 255-262, 425-462: "Revista de Archivos, Bibliotecas y Museos" " (1900), pp. 535-541, 662-667; "Revista de Àrchivos, Bibliotecas y Museos", 6 (1902), pp. 198 206, 372-382; "Revista de Archivos, Bibliotecas y Museos", 7 (1902bis), pp. 51-55; "Revista de Árchivos, Bibliotecas y Museos", 19 (1908), pp. 124-136;' "Revista de Archivos, Bibliotecas y Museos", 20 (1909) pp 277-289. Señala Lawrence con much razón que el modo fragmentario y Museos", 20 (1909), $\mathrm{pp}_{\text {i }}$ 277-289. Senala Lawrence con mucha razon que el modo fragmentario en que fue publicandose el estudio de Paz y Melia sobre la biblioteca del Hospital ha sido la causa bien accesible en el manejable volumen de Schiff. Charles FAULHABER, Libros y bibliotecas en la España medieval, Londres, 1987, pp. 68-69.

${ }^{10}$ Hay casos en que sí sabemos el origen de los libros. El notario Manuel Rodríguez de Sevilla, que recopiló una Crónica de España para el segundo conde de Benavente, hizo también la copia del Tratado de naturaleza angelica para el conde de Haro por encargo de su mayordomo don Rodrigo Dosormo: Isabel BECEIRA PITA, La biblioteca del Conde de Benavente a mediados del siglo XV y su relación con la mentalidady usos nobiliarios de la epoca "En la España medieval: Estudios en memoria del profesor D. Salvador de Moxó", ed. M. A. Ladero Quesada, Madrid, 1982, p. $135-145$.

${ }^{11}$ Claudia GIUYFRIDA, Per una datazione dell'Epitoma rei militaris dei Vegezio. Politica e propaganda nell'eta di Onorio, "Sicolorum Gymnasium", 34 (1981), pp p 25-26; Walter A. Rome's Fall and After, Londres, 1989.

${ }^{12}$ Charles R. SCHRADER, A handlist of extant manuscripts containing the De re militari of Flavius Vegetius Renatus, "Scriptorium", 30 (1979), pp. 280-305. 
traducciones al francés, 17 al inglés, 10 en italiano, 2 en español y otros tres en distintas lenguas. Los datos sobre los Vegecios latinos españoles tienen algunos errores que Rubio subsana ${ }^{13}$. Hay además algunos bilingües latínitaliano, latín-hebreo, latín-anglonormando, latín-francés.

La traducción de fray Alfonso se nos ha conservado con y sin glosas, y sin duda así debió difundirse. Los manuscritos que no incorporan las glosas son los siguientes:

Biblioteca Nacional de París, 2 mss.: Esp. 295, fols. 1r-70r y Esp. 211. fols. 1r-94r.

Real Biblioteca del Escorial, 2 mss. \&-II-18, fols. 1r-120r, y P-I-23, ción:

En cambio sí contienen dichas glosas los que detallamos a continua-

Biblioteca Menéndez y Pelayo de Santander, ms. 94, fols. 1r-93r (Catálogo Artigas \& Sánchez Reyes, $n^{\circ} 351$ ).

Biblioteca Nacional de Madrid, ms. 10445, fols. 151r-153v (muy fragmentario; sólo incluye el prólogo y los primeros capítulos). Procede de la biblioteca del Marqués de Santillana.

Real Biblioteca de Madrid, ms. II/569, fols. 1r-129r.

Las glosas de fray Alfonso son de dos tipos y no acompañan todo el texto por igual ${ }^{14}$. En el libro I hay una glosa explicativa y otra espiritual casi tras cada capítulo del romanceamiento de Vegecio, algunas incluso mucho más largas que lo traducido. En cambio en los libros siguientes escasean. En el segundo hay sólo dos glosas explicativas en los capítulos finales y ninguna espiritual. En el libro III hallamos una glosa explicativa tras el capítulo 10 y otra más tras el capítulo 13. Después del capítulo 17 hay una glosa espiritual y eso es todo. En el libro IV sólo hay una glosa explicativa que sigue al capítulo 39 y trata de los vientos y de los meses mejores para navegar.

Existió desde muy antiguo una auténtica tradición de tratadística militar de la que formaron parte textos como el Epitome o el Stratagematon de Sexto Julio Frontino. Vegecio da noticia de sus fuentes en dos ocasiones. En I. 8 cita a Catón el Censor, Cornelio Celso, Frontino, Paterno y las constituciones de Augusto, Trajano y Adriano. Más tarde, en II. 3, insiste en

\footnotetext{
${ }^{13}$ En El Escorial hay tres: ms. L. III. 33, fols. 1r-64v (de finales del siglo X, es el más antiguo de entre los hispanos); ms. f. IV. 28, fols. $1 \mathrm{r}-252 \mathrm{v}$; ms. O. III. 9, fols. 48r-80v (está encuadernado junto a Frontino). En la Biblioteca Nacional de Madrid: ms. 6036 , fols. $1 \mathrm{r}-45 \mathrm{v}$; encuadernado junto a Frontino) En la Biblioteca Nacional de Madrid: ms 6036 , fols. 1r-45v, ms. 9245, fols. 1r-51v. En la Biblioteca Universitaria de Salamanca: ms. 2137, fols. 1r-61v. En la Biblioteca Colombina: ms. 7-7-21, fols. 158r-171v. En la Biblioteca Provincial y Universitaria de Valladolid: ms 384 fols. $1 \mathrm{r}-80 \mathrm{v}$ (está encuadernado junto a Frontino): Lisardo RUBIO FERNÁNDEZ, Catálogo de los manuscritos clásicos latinos existentes en España, Madrid, 1984. Sabemos además que en 1409 existían dos copias en la biblioteca del papa Benedicto XIII en estudio del Epitome Rei Militaris, ed. María Teresa Callejas Berdones y María Felisa del Barrio Vega, Madrid, 1982. Hay otras dos traducciones más antiguas de J. Viana (Madrid, 1764) y de J. Belda Carreras (Madrid, 1929). La edición más moderna de Vegecio que conozco es: F.R. VEGETIUS, Epitoma rei militaris, ed. M.D. Reeve, Oxford, 2004.

${ }^{14}$ Jesús D. RODRÍGUEZ VELASCO, La Bibliotheca y los márgenes. Ensayo teórico sobre la glosa en el ámbito cortesano del siglo XV en Castilla. I: códice, dialectica y autoridad, "Humanista", 1 (2001), pp. 119-134.
} 
Catón el Viejo y en Frontino entre alii conplures. Esto no indica, insistimos, que sean sus fuentes directas. La tendencia general era suprimir los nombres de las fuentes inmediatas o copiar de autores anónimos de compendios ${ }^{15}$, y por tanto es muy posible que Vegecio esté usando epítomes del texto perdido de Frontino y de Paterno.

Hay paralelos convincentes entre algunas partes del libro III de Vegecio y ciertos fragmentos conservados del De re militari de Catón: mantenimiento de cierto orden de palabras, de términos técnicos obsoletos (principes, hastati, triarii, velites, ferentarii, accensi...) para la época de Vegecio, pero que eran frecuentes en el siglo III y II a. C. El relato del reclutamiento y el entrenamiento también parece vinculado a Catón. Pero sobre todo llama la atención el anómalo uso de la segunda persona del singular y de tuus-a-um en el libro III de Vegecio, y es lo que principalmente vincula este texto vegeciano con Catón ${ }^{16}$. Esta segunda persona tendrá una larga pervivencia y la volveremos a encontrar en el llamado Libro de la guerra.

Todos estos textos forman una larguísima cadena y se apoyan unos sobre otros durante siglos. Y la cadena no se detiene en Vegecio. También el Epitome dio lugar a otros epítomes y se hicieron de él resúmenes y compilaciones que originaron principalmente tres familias o grupos de textos, a saber: o Modesto.

1) Un resumen que aparece en los códices atribuido a Cicerón, Catón

Dalmasso considera que este opúsculo debió escribirse entre los siglos XIII y $\mathrm{XIV}$, en los tiempos de máxima difusión vegeciana con el fin de agilizar su uso $^{17}$. Si fue así, pronto adquirió vida independiente. Esta obrita aparece atribuida a Cicerón en los códices más antiguos. Ya Petrarca, cuando habla en sus Epistolae de rebus familiaribus (XXIV, 4) de las obras de Cicerón, cita entre ellas un De re militari. Más tarde aparece en los códices la atribución a Catón y a un tal Modestus. La biblioteca del Escorial conserva dos códices de este resumen como parte de las obras de Cicerón ${ }^{18}$. Modesto nunca existió. Se trata de una mixtificación literaria desvelada por el humanista François de Maulde en $1580^{19}$ y redescubierta en el siglo XIX. No existe ningún manuscrito de Modesto. El nombre de Modestus y el título De vocabulis rei militaris aparecen en 1474 asociados por primera vez en una edición romana.

\footnotetext{
${ }^{15}$ Pierre COURCELLE, Late Latin Writers and their Greek Sources, Cambridge Mass., 1969, pp. 78-79. También comenta este hecho: PLINIO, Hist. Nat. praef. 21.

${ }^{16}$ Flavius Renatus Vegetius, Epitome of military science, trad. e introd. N. P. Milner, Liverpool, 1993, p. 15.

${ }^{17}$ Lorenzo DALMASSO, La storia di un estratto di Vegecio, "Rendiconti del Istituto lombardo di Scienze e lettere". Milán, 1907, pp. 805-814. Para más noticia de este epitomecillo, vease Tomás GONZÁLEZ y Pilar SÁQUERó SUÁREZ-SOMONTE, Edición del De re militari de Modesto, en "Homenaje a L. Rubio. Cuadernos de Filología Clásica", Madrid, 1988, pp. 204-219.

${ }^{18} \mathrm{O}$. II. 12 , fol. $75 \mathrm{v}$. Incipit: Marci Tulli ciceronis de re militari incipit liber; R. I. 2, fol. 193r. Incipit: Liber Tullii de re militari.

${ }^{19}$ Flavii Vegetii Renati... De re militari quatour... Modestus de vocabulis rei militaris, imprimé par Maternus Cholinus, apud Maternum Cholinum, Cologne, Coloniae, 1580, f. 5r-5v.
} 
Este pseudo-autor cobra vida con la llegada de la imprenta y no tiene nombre hasta esta fecha, $1474^{20}$.

2) Opúsculo militar atribuido a Séneca.

Existe otro texto castellano que depende de Vegecio y continúa la tradición tratadística militar que se había iniciado en latín muchos siglos antes. En este caso el texto extraído de Vegecio está atribuido a Séneca. Round da noticia de que el Tractado de Seneca de cavalleria que se halla en la Biblioteca Nacional (ms. 17.803, fols. 111v-116v), es una versión con sentencias escogidas de la obra de Vegecio ${ }^{21}$. Afirma Blüher que en algunos códices se encuentra además bajo el título de Dichos de Seneca en el fecho de la cavalleria o también Tratado de la guerra, una traducción de fragmentos tomados del Epitome de Vegecio $^{22}$. Este pequeño compendio aparece en varios manuscritos colocado al final de las obras de Séneca traducidas directamente del original latino en el siglo XV por Alfonso de Cartagena ${ }^{23}$. Los títulos que lo encabezan son diversos. Además de los dos que hemos mencionado arriba, lo hallamos en los códices con otros más ${ }^{24}$ : Tratado de la guerra que fizo Seneca, Dichos de Seneca en el acto de cavalleria, Dichos de Seneca en el fecho de la cavalleria, Tratado de Seneca de la caballeria... Como queda ya señalado, la obrita está compuesta de sentencias y consejos de tipo general sobre la milicia y la guerra que han sido tomados de los tres primeros libros de Vegecio y romanceados. No son pocos los problemas que plantea. El primero tiene que ver con el original latino. ¿Existió un modelo latino de esta recopilación de sentencias?

${ }^{20}$ Jacques Ch. BRUNET, Manuel du libraire et de l'amateur de livres, París, 1850-1865, vol. III, col. 1783: "Le traite De Magistratibus est certainement de Pomponius Laetus, dont le nom se lit à la fin de l'ouvrage, dans 1'edition de 1474: mais, en disant que ce même Pomponius es le veritable auteur du traité De re militari et non Modestus, commo on l'a vu géneralement, $M$. Peyron n'aurait-il pas par hasard, confondu le premier de ces ecrits avez l'autre?". Lang en su edición sugiere que Pomponio Leto o algún discipulo suyo puede ser el compilador del texto, pero no argumenta nada que avale su hipótesis: Kar I sug pued Flavii Vegetii Renati Epitoma pere no argumenta nada que avale su hipotêsis: Karl LANG, ed. 69 avil Vegetil Renati Epitoma re En 1967 se reeditó con bastantes adiciones en el prólogo, pero manteniendo el texto sustancial.

${ }^{21}$ Nicholas G. Round, Las traducciones medievales catalanas y castellanas de las tragedias de Séneca, "Anuario de Ėstudios Medievales", 9 (1974-1979), p. 187, nota 1.

${ }^{22} \mathrm{Karl}$ A. BLÜHER, Séneca en España. Investigación sobre la recepción de Séneca en España desde el siglo XIII hasta el siglo XVII, Madrid, 1983, p. 141.

${ }^{23}$ Sobre Alfonso de Cartagena y su obra, véase M. MARTínEZ AÑIBARRO Y RIVES, Intento de un Diccionario Biografico y Bibliográfico de los autores de la provincia de Burgos, Madrid, 1889 (reimp. 1993), pp. 88-115; Luciano SERRANO, Los conversos D. Pablo de Santa María y D. Alfonso de Cartagena, Madrid, 1942, pp. 119-313; Francisco CANTERA BURGOS, Alvar García de Santa María. Historia de la judería de Burgos y de sus conversos más egregios, Madrid, 1952, pp. 416-464.

24-Biblioteca del Escorial, ms. T-III-4, fols. 213r-225r. Siglo XV. Incipit: Aqui comiença el tratado de la guerra que fizo Seneca. Véase Julián ZARCO CUEVAS, Catálogo de manuscritos castellanos de la Real Biblioteca de El Escorial, Madrid, 1926, vol. II, pp. 391-393.

-Idem, ms. T-III-7, fols. 234r-242v. Siglo XV. Incipit: Dichos de Seneca en el fecho de

caualleria. Véase Zarco Cuevas, op. cit. pp. 397-399. Aqui comiençan algunos dichos de Seneca en el fecho de la caualleria de rroma. Aqui comiençan algunos dichos de Seneca en el fecho de la caualleria de rroma.
-Ibidem, ms. 17.803 , fols. $111 \mathrm{v}-116 \mathrm{v}$. Siglo XV. Incipit: Aqui comiença tractado de Seneca

-lbidem, ms. 9613, fols. 285v-286v. Título: Dichos de Séneca en el hecho de la caballería de Roma.

-Ibidem, ms. 8188, fols. 214v-222v. Siglo XV. Título: Dichos de Seneca en el fecho de caualleria. 
Probablemente sí. El texto atribuido a Cicerón, Catón o Modesto de que hemos hablado más arriba no es el único resumen que se hizo en la Edad Media del Epitome rei militaris. Son muchos los compendios hechos a partir de esta obra, todos ellos anónimos: Vegetii Renati dicta et flores de re militari (Biblioteca Nacional de París, ms. 7233), Dicta et flores verborum Vegetii Flavii Renati de re militari (Bodleian Library de Oxford, ms. F. 5. 22), etcétera. Un modelo latino muy semejante al que sirvió de base a la traducción castellana se vertió al francés medieval ${ }^{25}$. Es por tanto probable que existiera un original latino para este texto castellano. Y cabe además preguntarse por qué motivo fue atribuido a Séneca. Sobre este punto hay que decir que se conservan manuscritos en que extractos de Vegecio aparecen encuadernados junto con otros de Séneca, y otros códices en que estos resúmenes vegecianos aparecen al final de la obra del filósofo cordobés, como es el caso del códice 205 de la Stiftsbibliothek de Rein ${ }^{26}$. Como sucedió en el caso de Villena y el Libro de la guerra es muy posible que en algún momento de la transmisión textual esta obrita militar fuese atribuida a Séneca por haberse encuadernado junto con los textos del filósofo. Además de esto hay que tener en cuenta que la atribución a Séneca de proverbios y sentencias, incluso de origen árabe, es un hecho constatado y sobre el que no merece la pena insistir.

Cuando Alfonso de Cartagena se dispuso a traducir a Séneca seguramente maneja un códice en el que ya está el compendio de sentencias de Vegecio y seguramente también los Dicta de Quinto Curcio ${ }^{27}$. Ahora bien, resulta extraño que no lo mencionara en su respuesta a la Questión fecha por el noble e magnífico señor don Iñigo López de Mendoça sobre el juramento de los caballeros ${ }^{28}$.

3) Libro de la guerra.

Hemos de considerar también como descendiente de Vegecio este opúsculo resumido a partir de la traducción de fray Alfonso de San Cristóbal. La relación entre esta versión y el Libro de la guerra, como aparece denominado en el manuscrito 6503 (Biblioteca Nacional), o 36 reglas de la milicia, como es llamado en el catálogo de la biblioteca del conde de Haro (Biblioteca Nacional, ms. res. 141) refiriéndose al códice 9608 (Biblioteca Nacional), es evidente si se comparan ambos textos. Uso las 36 reglas de la milicia (ms. 9806) del códice que perteneció al Hospital de la Vera Cruz que acabo de mencionar y el manuscrito 94 de la Biblioteca Menéndez Pelayo. He

\footnotetext{
${ }^{25}$ Leena LÖFSTEDT, Aucuns notables extraitz du livre de Vegece, "Neuphilologische Mitteilungen”, 83 (1982), pp. 297-312.

${ }^{26}$ Leena LÖFSTEDT, Vegèce au Moyen Âge: motifs et modifications des traducteurs et des copistes en "Homenaje' a Alvaro Galmés de Fuentes", Madrid, 1985, pp. 493-499.

${ }^{27}$ Gerald L. BOARINO, Los Dichos de Quinto Curcio. Traducción atribuida a D. Alfonso de Cartagena, "Bulletin Hispanique", 70 (1968), pp. 431-436. Tudorica O. IMPEY. Alfonso de Cartagena, traductor de Séneca y precursor del humanismo español, "Proemio" (III), 3 (1972), pp. 473-494.

${ }^{28}$ Íñigo LÓPEZ DE MENDOZa, MARQUÉS DE SANTILlana, Obras completas, ed. M.P.A.M. Kerkhof y A. Gómez Moreno, Barcelona, 1988, pp. 414-434.
} 
aquí algunos fragmentos que prueban claramente el vínculo entre uno y otro texto.

\section{FRAGMENTO 1}

36 reglas de la milicia (también llamado Libro de la guerra):

Prologo.

Todas las cosas por vso e por costumbre se acresçientan e conseruan, asy pequeñas commo grandes, segund manifiesta mente por espiriençia paresçe. Et commo el arte de la caualleria e batallas sea mas noble que ninguna otra, la qual guarda e acreçienta la libertad e dignidades e onrras, e conserua las prouinçias e rreynos, ca por ella es todo conseruado, cada cosa en su estado (fol. 64v).

Traducción de fray Alfonso:

Prólogo.

Todas las cosas por costumbre cada dia $\tau$ por uso aprouechan $\tau$ se acreçientan. Verdat non solamente en las cosas pequeñas, mas en las grandes, segun paresçe por experiencia. $\tau$ por quanto el arte de las batallas es mejor entre las otras cosas por quanto por ella, guardada la libertad de los omnes, la umanidat se acreçienta $\tau$ las prouinçias $\tau$ los rregnos $\tau$ los inperios son conservados en sus estados...(fol. 2r).

\section{FRAGMENTO 2}

36 reglas de la milicia (Libro de la guerra):

Capitulo primero.

Que cosa es hueste e commo cae por mengua de buena ordenança. Hueste es muchedumbre ayuntada de gente de cauallo e de pie, e asy lo dixieron los maestros delas armas. E sy los fechos leyeremos del rey Xerçes $e$ de Dario e de Poro e de otros rreys que ayuntaron pueblos sin cuento, manyfiesta mente paresçera que las grandes huestes abastadas de muchas gentes, por mengua de buena ordenança, son muy ayna vençidas, mas por mengua de aquella que por fuerça e vertud delos enemigos. Asy mesmo la muchedumbre delas gentes por muchas maneras lo pasa peor, ca en los camjnos syenpre tardan mas ... (fol. 65r).

Traducción de fray Alfonso:

Libro III, cap. 2.

... hueste es muchedunbre ayuntada de gente de caballo $\tau$ de pie para fazer batalla $\tau$ asi lo dixieron los maestros $\tau$ doctores de las armas. Et si los enxenplos leyeremos de Xerses $\tau$ de Dario $\tau$ de Poro $\tau$ de Mitridas $\tau$ de otros reyes que ayuntaron $\tau$ armaron pueblos sin cuento, manifiestamente pareçera que muchas huestes abastadas de muchas gentes fueron vençidas, mas por ser muchas que non por fuerça $\tau$ virtud de los enemigos. Et la rrazon lo dize, ca por muchas maneras lo pasa peor la mas gente $\tau$ mayor muchedunbre, ca en los caminos siempre es mas tardiosa...(fol. 46v). 
FRAGMENTO 3

36 reglas de la milicia (Libro de la guerra):

Capitulo XIIII.

Quantas legiones leuauan los antiguos ala batalla.

Fallase que los consoles romanos non leuauan alas batallas mas de dos legiones con sus ayudas contra muy poderosos enemjgos. E estos sabjan tanto en las armas e aujan tanta fiusia en aquellos que entendjan que, para vençer qual quier batalla por grande que fuese, bastauan aquellos; onde es nesçesario que fynque con vitoria la tyerra, de la qual el señor de aquella e los suyos son sabidores de la arte de pelear e batallas (fol. 69v).

Traducción de fray Alfonso:

Libro II, cap. 4.

En todos los actores $\tau$ fazedores del arte de la caualleria se falla que cada uno de los consules rromanos leuo alas batallas mas que dos legiones con sus ayudas de compañeros contra muy poderosos enemigos $\tau$ estas auian tanto uso de las armas $\tau$ tanta fiusia que entendian $\tau$ creian que para vencer qual quier batalla podian abastar (...) Onde cosa neçesaria es que finque con victoria la comunidad $\tau$ la tierra donde es señor el emperador que sabe $\tau$ ha el arte de las batallas... (fol. 32r).

El anónimo autor del Libro de la guerra resume sólo algunas partes del romanceamiento de fray Alfonso. Para el prólogo, por ejemplo, selecciona el comienzo del prólogo general del Epitome y los de los capítulos 1 y 2 del libro I de Vegecio. El compilador se vale únicamente de los libros I, II y III y no emplea el último. En concreto, resume 4 capítulos consecutivos del libro I, los dedicados al asentamiento de la hueste; 6 capítulos, parte consecutivos y parte no, del libro III, que tratan de medidas sanitarias, provisiones, desplazamientos y huestes inexpertas; 9 capítulos, parte consecutivos y parte no, del libro II sobre el mayor o mayoral de la hueste y otros cargos, y sobre su organización; 16 capítulos del libro III, en su mayor parte consecutivos y no usados previamente, de manera que el libro III esta prácticamente al completo en el Libro de la guerra, aunque ordenado de un modo diferente y con cuñas de otros libros y capítulos de la traducción de Vegecio.

A continuación señalaremos el libro y capítulo de Vegecio en la versión de fray Alfonso de que proceden cada uno de los capítulos del Libro de la guerra:

Prólogo ... Inicio del prólogo general de Vegecio, inicio de los libros I. 2 y II. 2, con algunos comentarios breves de transición que son obra del autor del resumen.

Capítulo 1 ... Vegecio III. 1.

Capítulo 2 ... Vegecio I. 22.

Capítulo 3 ... Vegecio I. 23.

Capítulo 4 .... Vegecio I. 24. 
Capítulo 5 ... Vegecio I. 25.

Capítulo 6 ... Vegecio III. 2. Capítulo 7 ... Vegecio III. 3. Capítulo 8 ... Vegecio III. 6. Capítulo 9 ... Vegecio III. 7. Capítulo 10 ... Vegecio III. 8.

Capítulo 11 ... Vegecio III. 10. Capítulo 12 ... Vegecio II. 10. Capítulo 13 ... Vegecio II. 3.

Capítulo 14 ... Vegecio II. 4. Capítulo 15 .... Vegecio II. 5 . Capítulo 16 ... Vegecio II. 6.

Capítulo 17 ... Vegecio II, 7. Capítulo 18 ... Vegecio II. 9.

Capítulo 19 ... Vegecio II. 11. Capítulo 20 ... Vegecio II. 13. Capítulo 21 ... Vegecio III. 4.

Capítulo $22 \ldots$ Vegecio III. 5. Capítulo 23 ... Vegecio III. 9.

Capítulo 24 ... Vegecio III. 11.

Capítulo 25 ... Vegecio III. 12.

Capítulo 26 .... Vegecio III. 13.

Capítulo 27 ... Vegecio III. 14.

Capítulo 28 ... Vegecio III. 15.

Capítulo 29 ... Vegecio III. 17.

Capítulo 30 ... Vegecio III. 18.

Capítulo 31 ... Vegecio III. 19.

Capítulo 32 ... Vegecio III. 20.

Capítulo 33 .... Vegecio III. 21.

Capítulo 34 .... Vegecio III. 22.

Capítulo 35 ... Vegecio III. 25.

Capítulo 36 ... Vegecio III. 26.

Queda así establecida definitivamente la procedencia del Libro de la guerra, obra cuyo origen ha dado lugar a muchos errores que se han repetido desde la atribución equivocada de su primer editor, Lucas de Torre, hasta hoy. Así Viña Liste cuando se refiere Vegecio y a la traducción de fray Alfonso de San Cristóbal en su estudio preliminar del Doctrinal de los cavalleros, menciona "otra traducción" hecha antes y titulada el Libro de la guerra $^{29}$. Las referencias erróneas son bastantes y llegan hasta nuestros días ${ }^{30}$. Esta es una de las razones por las que he consideratu útil su reedición, no sólo para cubrir las lagunas que habían quedado en la meritoria edición de Lucas de Torre sino también para dar cuenta de la verdadera genealogía de este texto. El tratadito en definitiva llamado Libro de la guerra o 36 reglas de la milicia es el único descendiente genuinamente castellano de Vegecio, puesto que está hecho sin lugar a dudas a partir de una traducción a esta lengua.

${ }^{29}$ Alonso de CARTAGENA, Doctrinal de los cavalleros, ed. José María Viña Liste, Santiago de Compostela, 1995, p. XLVIII.

${ }^{30}$ Alan D. DEYERMOND, La literatura perdida en la Edad Media: catálogo y estudio, Salamanca, 1995, p. 263. José Francisco RUIZ CASANOVA, Aproximación a una historia de la traducción en España, Madrid, 2000, p. 98. 
Hasta el Renacimiento, Vegecio mantuvo intacto su prestigio junto con Frontino, Aeliano y sus Tacticas $^{31}$, y Modesto, y son muchas

las copias que de estos se hacen desde 1487. Sin embargo, en esta época aparecen también las primeras lamentaciones de autores que se quejan de que Vegecio se haya conservado, y no las fuentes que él cita y en las que se apoya. Porque el Epitome rei militaris es un compendio tardío que resume y unifica, corta y pega, si bien con una idea de conjunto bastante definida, a Catón, Celso, Frontino y Paterno, según afirmación del propio Vegecio, pero lo más probable es que Vegecio trabajase ya con materiales epitomizados de los textos que nombra. O sea, Vegecio está escribiendo el resumen de otros resúmenes. Su prestigio se resentirá de ello notablemente en el Renacimiento, y así, cuando Maquiavelo escribe su Arte de la Guerra en Florencia en 1521 hace notable uso de Frontino, Polibio y Tito Livio para complementar las deficiencias de Vegecio, y P. Scriverius considera a Vegecio un pobre sustituto de Polibio que confunde de época las instituciones romanas ${ }^{32}$. Los tratadistas renacentistas tienen sus razones. El arte de la guerra sufrió una revolución considerable entre los siglos XV-XVI con las armas de fuego. En la misma época se constituye el corpus de los autores militares antiguos, veteres scriptores de re militari, que conocen un verdadero éxito de edición entre 1475-1550. A partir de 1487, Vegecio aparece asociado a Frontino y a otros veteres scriptores de menos importancia como el Pseudo-Modesto y Aeliano. Se trata de un auténtico enciclopedismo que no es completamente nuevo en relación con la Edad Media, pero la asociación de algunos de estos autores deja de ser casual. La primera edición colectiva de Vegecio, Frontino, Aeliano y el Pseudo-Modesto data de 1487, es obra del humanista Giovanni Antonio Sulpizio da Veroli y se imprime en Roma ${ }^{33}$. Después vendrán otras muchas como esta y semejantes, casi siempre bajo el nombre común de Vegecio. Sin embargo, las colecciones boloñesas de 1496 y 1505 del corpus

\footnotetext{
${ }^{31}$ Teodoro de Gaza o Tesalónica y Antonio Panorimitano tradujeron para Alfonso de Aragón, en plena euforia humanística, a Aeliano que es un autor militar griego tardío (siglo II). Este será el unico griego que se incorpora al corpus de re militari. El tratado de Aeliano es bastante ârido, muy táctico, con esquemas de tropas y combatientes representados por letras, y por esto mismo, muy táctico, con esquemas de tropas y combatientes representados por letras, y por esto mismo, interesantísimo para los nuevos ejércitos que estaban surgiendo con la superación de la guerra medieval. Sus planteamientos debieron influir en la guerra moderna que cobra forma entre los
siglos XV y XVI. Suizos y lansquenetes encontraron interesantes sus formaciones con pica, cuya siglos XV y XVI. Suizos y lansquenetes encontraron interesantes sus formaciones con pica, cuya
eficacia ellos mismos estaban probando. Se discute la influencia que ejercieron los suizos y este eficacia ellos mismos estaban probando. Se discute la influencia que ejercieron los suizos y este
tipo de formaciones en la configuración de los tercios españoles, que representaron una novedad tipo de formaciones en la configuración de los tercios españoles, que representaron una novedad la traducción latina del texto de Aeliano con el título De instruendis aciebus. Hay un ejemplar de esta editio princeps en la biblioteca Houghton, en Harvard, que es el que yo he consultado. AELIANO, Claudil Aeliani et Leonis imperatoris Tactica sive De instruendis aciebus, ed. Werne Hahlweg, Osnabrück, 1981. Existe una traducción inglesa: AELIANUS Tacticus, The tactics of Aelian comprising the military system of Grecians, illustrated with notes and explanatory plates, Aelian, comprising the military system of Grecians, illustrated with notes and explanatory plates, leerse en: Walter E. KAEGI, Some thoughts on Byzantine Military Strateoy Brookline Muss, 1983, pp. 10-13 y John F. HALDON, Warfare, State and Society in the Byzantine World, Londres, 1999 , pp. 37-38.

${ }^{32}$ N.P. MILNER, Vegetius and the Anonymus De rebus bellicis, Oxford, 1991, cap. 7. Es tesis doctoral citada por Lynch: Nicolás MAQUIAVELO, Art of War, ed. Christopher Lynch, Chicago, 2003 , p. xi.

${ }^{33}$ Peter G. BIETENHOLZ, Contemporaries of Erasmus. A Biographical Register of the Renaissance and Reformation, vol. III, Toronto, 1987, p. 300.
} 
veterum scriptorum de re militari llevan el nombre de Frontino. Es una novedad introducida por el editor Giovanni Antonio de Benedictis, lo que testimonia el prestigio creciente de Frontino en el Renacimiento. Esta colección de veteres scriptores de re militari se irá acrecentando en latín y otras lenguas con el anónimo De rebus bellicis, fragmentos de Catón, Cincio e incluso extractos de Polibio ${ }^{34}$.

A pesar de que los consejos de Vegecio están concebidos para un tipo de ejército muy distinto del medieval, hay una parte notable de las enseñanzas de Vegecio que tendrá eco en la Edad Media, ya que son aprovechables y proporcionan conocimientos que ni la épica ni la narrativa ni los exempla ofrecidos por otros autores, como Frontino, podían ofrecer: una noción de la disciplina y del entrenamiento que el hombre medieval admiraba ${ }^{35}$. Tampoco eran de desechar otras informaciones relacionadas con el cerco y defensa de ciudades. El Epitome es el más importante testimonio que legó la Antigüedad sobre la milicia, o mejor dicho, aquel que el Medievo escogió como referente ${ }^{36}$.

Varios autores de los siglos XIV y XV se declaran lectores y hasta discípulos de Vegecio, así Froissart, Jean de Bueil, Jean Molinet ${ }^{37}$. Cuando al duque de Borgoña se le anegan las tiendas en el sitio de Neuss, Molinet lo critica en sus Crónicas por no haber aprovechado las enseñanzas de Vegecio, lo que hubiera impedido tal desdicha ${ }^{38}$. La influencia de Vegecio se deja sentir desde Rabano Mauro al Rosier des guerres de Pierre Choisnet ${ }^{39}$. Hay entre 11 y 14 ediciones de Vegecio en el siglo XV y 25 ediciones en el siglo XVI, de las que 14 son traducciones ${ }^{40}$. Pero vamos a la difusión de Vegecio en Castilla.

\footnotetext{
${ }^{34}$ Philippe RICHARDOT, Vegèce et la culture militaire au Moyen Age (Vème-XVème siècle), París, 1998, pp. 232-237 y Frank AUSBILDUNG, Die Epitoma rei militaris des Vegatius zwischen ritterlicher. Ausbildung und gelehrt-humanistischer Lektüre: $\mathrm{Zu}$ einer witeren unbekannten dutschen Übersetzung aus der Wiener Artistenfakultät, "Beiträge zur Geschichte der Deustchen Sprache und Literatur", 124 (2002), pp. 302-338.

${ }^{35}$ Maurice KeEN, La caballería, Barcelona, 1989, p. 150.

${ }^{36} \mathrm{El}$ Epitoma rei militaris no es la única obra de Vegecio, autor también de un tratado de veterinaria, Mulomedicina: A Neumann, Publius (Flavius) Vegetius Renatus: Paulys-Wissowa Real-Encyclopädie, Supl. X, 1965, col. 992-1020.

${ }^{37}$ Vease Philippe Contamine, La guerre au Moyen Âge, París, 1992, p. 351-389.

${ }^{38}$ Jean Molinet, Chroniques, ed. Georges Doutrepont y Omar Jodogne, Bruselas, 1935-37, vol. I, pp. 434-436.

${ }^{39}$ Sobre la tradición medieval de Vegecio : Charles R. SCHRADER, The Ownership and Distribution of the Manuscripts of De re militari of Flavius Vegetius Renatus before the year 1300 New York, 1976; Foster H. SHERWOOD, Studies in Medieval uses of Vegetius' Epitoma re militaris, Las Ángeles, 1980; J. A. WILSMAN, L' Epitoma rei militaris de Vegecce et sa fortune au Moyen "Age, "Le Moyen Âge", 85 (1979), pp. 13-31 ; del mismo autor Flavius Renatus Vegetius, "Catalogus Translationum et Commentariorum", vol. IV, 1986, pp. 175-184; Philippe RICHARDOT, L'influence médiévale du De re militari de'Vegèce, en B. Colson y $\mathrm{H}$. CoutauBegarie, eds. Pensée strategique et Humanisme. Actes du Colloque International organisé les 19 , 20 et 21 mai à Namur, Paris, 2000, pp. 27-46. R. SABLYROLLES, Bibligraphie sur " Epitoma re militaris de Vegèce", "Cahiers du Groupe de recherche sur l'armée romaine et les provinces", 3 (1984), pp. 139-146.

${ }^{40}$ Curt F. BÜHLER, The Earliest Appearances in Print of Vegetius, "Gutenberg-Jahrbuch", 6 (1956), pp. 91-93
} 
Vegecio aparece ya en las Partidas, en el título de la caballería y más adelante en el título de la guerra. Para Francisco García-Fitz, la influencia de Vegecio en el compendio legal es muy limitada. Su punto de vista es totalmente opuesto al de Contamine, para quien Alfonso X copia íntegramente a Vegecio ${ }^{41}$. La afirmación de Contamine es exagerada y la de García Fitz también. El Rey Sabio conoce el texto y lo cita sin error. Lo que sucede es que Alfonso interpreta el tratado vegeciano a su modo medieval, y así, por ejemplo, al tratar de la elección de los caballeros, afirma que debe hacerse más según el pundonor del individuo que por su fuerza física, pues es la vergüenza la que impide huir en la batalla ${ }^{42}$. Aquí Vegecio habla más que de honor, de excelencia moral, y por supuesto, no se refiere a los caballeros sino a la elección de reclutas para las legiones.

Fray Juan Gil de Zamora escribió su De preconiis Hispaniae en el último cuarto del siglo XIII con el pedagógico propósito de servir a la educación del entonces príncipe Sancho, luego rey Sancho $\mathrm{IV}^{43}$. Los dos últimos libros de la obra, el XI y el XII, dentro del contexto didáctico general, están dedicados a la enseñanza del arte de la guerra. Son un conjunto de sentencias, máximas y breves consejos que en ocasiones resultan un poco inconexos, pero que van todos encaminados a la formación militar. Están concebidos para aplicarse a una variada casuística bélica y no son otra cosa que una adaptación y selección de algunas partes del Epitome rei militaris.

De la fama de Vegecio son prueba tanto las citas verdaderas como las falsas, dicho de otro modo, lo atribuido a Vegecio que por ningún lado se encuentra. Se da el caso, ya preocupante, de que, de las 29 veces que lo cita Gil de Zamora en el libro XII de su De preconiis Hispaniae, ninguna corresponde con el texto vegeciano a quien explicítamente afirma referirse, aunque el tipo de tácticas recomendadas está entroncada con la tradición romana que Vegecio representa ${ }^{44}$. ¿Qué prueba esto? Evidentemente que Vegecio es una de las autoritates maximae, si no la que más, de lo militar para el hombre letrado medieval, independientemente de que realmente se conociera su texto ${ }^{45}$. Es el nombre que se aplica a una larguísima tradición que arranca en los tiempos gloriosos de Roma y que fue durante generaciones resumida y compendiada por autores conocidos y anónimos, que copiaron unos de otros exempla et sententiae de procedencias muy variadas. Vegecio es el nombre que acredita cualquier enseñanza militar, aunque no pocas veces,

\footnotetext{
41 "La influencia real de la obra de Vegecio sobre los redactores de las Partidas, al igual que sobre don Juan Manuel puede ser, como poco, puesta en duda": Francisco GARCílA FITZ, La Estudios Medievales" Estudios Medievales" 19 (1989) p. 274. Las partes de la magna compilación objeto de tan II, xxiii que podemos casi considerar un tratado de didáctica militar. En ambas es visible, pero limitada, la influencia de Vegecio.

${ }^{42}$ Partidas II, xxi, ley 2. Epitome I, 7.

${ }^{43}$ Juan GIL DE Zamora, De preconiis Hispaniae, ed. M. De Castro, Madrid, 1955.

${ }^{44}$ Ed. M. de CASTRO, p. 16.

${ }^{45}$ GARCÍA FITZ, La didáctica militar, pp. 271-283.
} 
la información no procede de él. Su reputación incomparable justifica que fuese resumido, incluso a partir de una traducción.

El caso de don Juan Manuel es significativo. En el Libro del cavallero et del escudero (cap. XIX), aconseja lo siguiente: Si vos quisieredes saber todo esto que me preguntastes de la cavalleria conplidamente, leed un libro que fizo un sabio que dizen Vejeçio et lo fallaredes todo ${ }^{46}$. A pesar de esto no es apreciable la influencia de Vegecio en don Juan Manuel, que expone su propia visión de la guerra y no coincide con Vegecio sino en consideraciones de tipo muy general, por las que difícilmente se puede considerar al romano una fuente manuelina. El autor medieval recurre a la auctoritas para dar fuste a su propia obra. Quien sabe de milicia, trata de ella o de ella escribe, tiene que conocer o siquiera mentar a Vegecio, si no su competencia será puesta en duda.

La obra Livre des faits d'armes et de chevalerie de Christine de Pisan es otra ilustración de lo mismo ${ }^{47}$. Este texto está inspirado en el Arbre de batailles de Honore Bouvet y en la traducción de Vegecio de Jean de Vignai. El tratado de Christine de Pisan, traducido por William Caxton, tuvo un gran éxito en lengua inglesa bajo el título The book of fayttes of armes and of chyvalrie y se publicó en 1487. Pues bien, el texto terminó siendo atribuido en francés primero, luego en inglés y otras lenguas a las que fue traducido, a Vegecio, y el nombre de Christine fue aplastado por la auctoritas (ella además contaba con la desventaja de ser mujer) a pesar del notable empeño de adaptar el modelo romano a las necesidades de la artillería y de la caballería a principios del siglo $\mathrm{XV}^{48}$.

También Juan de Mena cita a la autoridad militar por excelencia. En la copla 38 de su Coronación a él se refiere: vi la fama gloriosa / del arte cavallerosa / que reconpuso Vegeçio ${ }^{49}$ y en el Cancionero de Baena leemos: Yo lei en el Vegeçio / que compuso "Las batallas" / se que sopo assi pintallas / e las puso en muy grand preçio ${ }^{50}$. Nombraron a Vegecio tanto los que lo habían leído como los que no, porque era el autor que había que mentar cuando se hablaba de batallas. En la introducción a un dezir satírico escrito por Gómez Manrique hecha por Pero Díaz de Toledo para don Alonso Carrillo encontramos de nuevo a Vegecio. Cuenta aquí Pero Díaz la sabrosa

\footnotetext{
${ }^{46}$ Don JUAN MANUEL, Floresta de varia caballería: Raimundo, Alfonso X, Don Juan Manuel,
ed. Luis Alberto de Cuenca, Madrid, 1975 , p. 258. Cuenca sigue aquí la edición de José María Castro y Calvo y Martín de Riquer en Obras completas, Barcelona, 1955, pp. 11-72.

${ }^{47}$ Charity C. WILlard, Pilfering Vegetius? Christine de Pizan's Faits d'Armes et de Chevalerie en Women, the Book and the Worldly, ed. Leslie Smith y Jane Taylor, Brewer, 1995, pp. 31-37.

${ }^{48}$ Véase Suzanne SOLENTE, Christine de Pisan, en Histoire litteraire de la France, París, 1974, vol. 40, p. 405 y Berenice A. CARROLL, The causes of war and quest for peace: Christine de Pisan and early peace theory, en Au champú des scriptures ("IIIIème Colloque Internacional de Pisan and early peace theory, en Au champú des scriptures ("IIIème Colloque Internacional
sur Christine de Pisan"), ed. Eric Hicks, Diego González y Philippe Simon, Paris, 2000, pp. 337-

${ }^{49}$ Ed. Miguel Ángel PÉrez PrIEgo, Barcelona, 1989, p. 191.

${ }^{50}$ Eds. Brian Dutton y Joaquín González Cuenca, Madrid, 1993, 586+, 16a-d.
} 
anécdota de las matronas romanas que se cortaron el pelo en un momento de extrema necesidad para hacer guitas para los puentes ${ }^{51}$.

Algunas sentencias vegecianas hicieron fortuna y todavía son famosas, como el tantas veces mentado "si quieres la paz, prepara la guerra". Juan Gil de Zamora lo menciona y recalca su importancia: qui desiderat pacem preparet bellum (libro XI, títulos 10 y 12). También don Juan Manuel se hace eco en el Libro del cavallero et del escudero, donde afirma: dizen los cavalleros en un proverbio que el que quiere bevir en paz, que se apareje para la guerra (cap. XLVI) ${ }^{52}$. Sin embargo, no atribuye a Vegecio la máxima. La influencia del Epitome debe ser medida con cuidado. Ni siquiera cuando el autor, Vegecio, es mencionado, podemos estar seguros de que la obra era conocida. Mucho menos cuando no se da el caso, y los comentarios militares son consejos muy generales que también pueden atribuirse al sentido común y a la práctica cotidiana de hombres de vida guerrera ${ }^{53}$.

La influencia de Vegecio es especialmente importante en Rodrigo Sánchez de Arévalo y su Suma de la política, y aquí sí demuestra el autor ser un buen conocedor del Epitome. Trata don Rodrigo de cómo deben ser fundadas y edificadas las ciudades y fabla otrosi del buen regimiento e recta polecia que deue auer todo reino o cibdad ${ }^{54}$. El libro I, que consta de 18 Consideraciones, dedica las siete últimas a la ciudad en tiempo de guerra. Nombra aquí a Vegecio en varias ocasiones y las referencias son veraces. En la Consideración XII, que versa de los aparejos y provisiones que se han de proveer antes de la guerra son muchos los consejos tomados del Epitome ${ }^{55}$.

La última parte de esta Consideración es casi un resumen del libro III del romano sobre dónde y cómo aposentar la hueste, el necesario conocimiento de los caminos por donde ha de transitar, la atinada elección del lugar para la batalla, etcétera. En definitiva, lo que encontramos en el Libro de la guerra. En la siguiente Consideración, don Rodrigo vuelve a Vegecio para tratar de la necesidad de castigar las desobediencias y las discordias entre

\footnotetext{
${ }^{51}$ Raymond FoulchÉ-DELBOSC, Cancionero castellano del siglo XV, Madrid, 1915, vol. II. Las menciones a Vegecio aparecen en las páginas $131 \mathrm{a}$ y $134 \mathrm{~b}$ en la Introduçión al dezir que conpuso el noble cavallero Gomez Manrrique, que yntitula: Exclamación e querella de la gouernaçión, al muy noble e muy reuerendo señor, su singular señon
la graçio de Dios arcobispo de Toledo, por el doctor Pero Diaz.

${ }^{52}$ Ed. Cuenca, p. 325.

${ }^{53}$ Según Tate, Hernando del Pulgar en sụs Claros varones de Castilla presenta a don Rodrigo Manrique como un seguidor de los principios vegecianos. Las palabras de Hernando del Pulgar que dan lugar a esta conclusión son las siguientes: "Preciávase [don Rodrigo] mucho de que sus criados [la gente de su casa] fuesen dispuestos para las armas. Su plática con ellos era la manera del defender y del ofender el enemigo, y ni se dezía ni fazía en su casa acto ninguno de molleza enemigo del oficio de las armas. Quería que todos los de su compañía fuesen escogidos para aquel exercicio y no convenía a ninguno durar en su casa si en él fuese conoscido punto de covardía. Y si alguno venía a ella que no fuese dispuesto para el uso de las armas, el grand exercicio que avía y veía en los otros fazía ábile y diestro en eflas" (Hernando del PULGAR, Claros varones de Castilla, ed. Robert B. Tate, Oxford, 1971, p. 49).

${ }^{54}$ Mario PenNa, ed., Prosistas castellanos del siglo XV, Madrid, 1959, p. 251.

${ }^{55}$ Al officio del buen politico pertenesce, ante de la guerra, fazer de lexos grandes $e$ abundantes aparexos de las cosas necessarias a la guerra, las quales, como dice Vegecio -De re militari-han de ser luengo tiempo pensadas e buscadas. Ca dize el dicho Vegecio fermosamente qu'el luengo e bien proveido aparexo y la preparación de la guerra bien pensada, trahe brevemente victoria: Ed. Penna, p. 269. Don Rodrigo copia aquí a Vegecio III, cap. 3.
} 
caballeros inspirándose en el libro III, cap. 9. Vegecio también es mentado en el Vergel de príncipes donde hallamos la famosa máxima: e asi dice Vegecio: Quien desea la paz, apareje la guerra ${ }^{56}$. En la enumeración de las loables cualidades que se derivan del ejercicio de la caza señala que como dize Vegecio, quien osa acometer e esperar a un bravo e fiero puerco, bien osara acometer e esperar a su enemigo. Pueden señalarse otros muchos ejemplos ${ }^{57}$.

Hay autores en los que esperaríamos alguna mención a Vegecio que sorprende no hallar. Ni el Marqués de Santillana ni Alfonso de Cartagena lo nombran en su discusión erudita sobre el juramento de los caballeros. Sin embargo, el obispo de Burgos parece estar copiando al romano al tratar de lo mismo en su Doctrinal de los cavalleros ${ }^{58}$. En cuanto al Libro de la guerra, el descendiente castellano del Epitome, es imposible saber cuál fue su difusión real, al margen de las dos copias que conservamos. Carece de un título específico y no tiene autor conocido. Si alguien se valió de él y copió alguna de sus partes, bien podríamos confundirlas con la traducción de fray Alfonso de San Cristóbal de que procede. En cualquier caso, este centón castellano nace como consecuencia del intenso interés por la caballería y sus instituciones que, presente en toda la Edad Media, cobra un nuevo brío en Castilla a finales del siglo XIV, y alcanza su apogeo en el siguiente. Rodríguez Velasco llama a esta etapa "de expansión y polémica". Se refiere a los años que van de 1390 a 1492. En este tiempo la caballería castellana convive con la cortesía, y al mismo tiempo, polemiza e indaga sobre lo que ella misma es, atravesada por una especie de crisis existencial ${ }^{59}$. Busca vincular sus orígenes a la milicia romana y quiere no ser sólo guerrera sino también culta y política. Se escriben bastantes tratados sobre caballería en los que se discute su ser y su función social. Baste mencionar a Alfonso de Cartagena, Diego de Valera, Alonso de Palencia... Por eso se traduce a Vegecio y Frontino, y a otros autores medievales como el francés Honoré Bouvet o el italiano Leonardo Bruni. Vegecio ya había dejado su huella mucho antes de ser traducido. Su versión y su resumen son consecuencia de su fama, y no causa de ella. Pero ocurre que ahora muchos nobles que no saben latín, o lo descifran con

\footnotetext{
${ }^{56}$ Ed. Penna, p. 319.

${ }^{57}$ Ed. Penna, p. 327. Aquí Arévalo también se refiere, casi traduciendo a Vegecio de manera literal, a la disçiplina como única razón por la que los romanos vencieron a franceses, hispanos, germanos, etcétera (Vegecio I, 1), y volverá a mencionar lo mismo en la Suma de política (Ed. Penna, p. 306).

${ }^{58}$ Compárense Epitome, II, 5: "milites scripti... iurare solent; et ideo militiae sacramenta dicuntur. Iurant autem per Deum et per. Christum et per Spiritum sanctum et per maiestatem imperatoris, quae secundum Deum generi humano diligenda est et colenda. Nam imperator cum Augusti nomen accepit, tanquam praesenti et corporali Deo fidelis est praestanda devotio inpendendus pervigil famulatus. Deo enim vel privatus vel militans servit, cum fideliter cum diligit qui Deo regnat auctore. Iurant autem milites omnia se strenue facturos, quae praeceperit imperator, numquam deserturos militiam nec mortem recusaturos pro Romana republica", y Alonso de CARTAGENA, Doctrinal de los cavalleros, ed. J. M. Viña Liste, Santiago de Compostela, 1995, p. 39: “juran cuando resciben orden de cavallería, así como non se escusar de muerte tomar por su ley, si menester fuere, nin ser en consejo en ninguna manera para menguarla, mas acrecentaran lo más que pudieren. Otrosí que non dubdaran de morir por su señor natural, non tan solamente desviando su mal e su daño, mas acrecentándole su pro e su onra cuanto más pudieren e sopieren; y eso mesmo farán por pro comunal de su tierra".

${ }^{59}$ RodRÍGUEZ VELASCO, El debate sobre la caballería, p. 376.
} 
dificultad, quieren leer en la lengua vulgar los principios de la milicia romana y las hazañas de sus incomparables caudillos, porque estos son los ancestros a los que quieren parecerse. Es más, tienen derecho a parecerse porque son sus ancestros. Despunta y pronto se robustece un interés inusitado por los clásicos, especialmente de re militari. Vegecio se romancea y se resume. De Frontino se hacen tres versiones ${ }^{60}$. Se traduce como nunca antes en Castilla.

No es este lugar para extenderse sobre el asunto, pero el Vegecio castellano y su vástago deben considerarse una parte, pequeña, pero no insignificante, del gran cambio cultural que la nobleza castellana protagoniza en el siglo XV. La aristocracia de Castilla admira a Julio César y a los que como él manejaron la pluma y la espada con garbo parejo. De este ayuntamiento singular de caballería y emulación clasicista, nace una clase guerrera medieval y caballeresca, pero novísima, que dará poetas y escritores, bibliófilos, traductores y mecenas, sin bajarse del caballo. Desde Santillana a Garcilaso, serán los rectores de un cambio histórico de muy visible importancia.

\section{NUESTRA EDICIÓN}

El manuscrito 6503 de la Biblioteca Nacional que edita Lucas de Torre tiene un incipit que no se encuentra en el texto que editamos: Empieça el libro de la guerra, que escribo por utilidad i beneficio de todos, y principalmente para los Caballeros a quienes pertenece mas por raçon de la nobleza $\tau$ buen gobierno, cuidando en las batallas de saber offender $i$ defender, ganando premio, honrra $i$ gloria ${ }^{61}$. Edito el códice 9608 (en lo sucesivo A) de la misma biblioteca. En el mismo folio en que acaba la traducción anónima del Strategematon de Sexto Julio Frontino, y sin transición ni indicación de título, comienza este otro texto. Desaparece la numeración antigua en romano que puede leerse en los márgenes superiores a veces y que no es la que sigo. La seguida por mí es árabe y moderna. Comienza con la tabla de capítulos del texto. El título 36 reglas de la milicia lo he tomado del catálogo de manuscritos de la biblioteca del conde de Haro (Biblioteca Nacional, ms. res. 141, fol. 12v), que así lo llama. Señalo en nota las variantes con respecto al texto de Lucas de Torres (en lo sucesivo B) y las lagunas que indica este editor y que he completado.

\footnotetext{
${ }^{60}$ Las traducciones del siglo XV son anónimas. La del manuscrito 10198 (Biblioteca Nacional de Madrid) perteneció al Marqués de Santillana: Mario SCHIFF, La bibliothéque du Marquis de Santillane París, 1905 (reimp. Amsterdam.1970), pp. 34-36. Otra versión distinta se contiene en los códices 9608, 10204 y 9253. En 1516 se editó una nueva traducción, obra de Diego Guillén de Avila. La catalogación y noticia de estos manuscritos ha estado plagada de errores. Por ejemplo, el manuscrito 9253 fue atribuido a Diego Guillén de Avila: Ch. Faulhaber, Bibliography of Old Spanish Texts, Madison, 1984, p. 129 . El error lo reproducen Ariadna y Beta. Vease María Elvira ROCA BAREA, Diego Guillén de Avila, autor y traductor del siglo XV, "Revista de Filologia Española", 86 (2006), pp. 373-394.

${ }^{61}$ TORRE, Libro de la guerra, pp. 497-498.
} 
He procurado ceñirme escrupulosamente al texto que he tomado como base. Respeto pues las grafías originales, excepto la $\mathrm{R}$ y s sigmática. He modernizado el uso de mayúsculas y puntuación. Desarrollo las abreviaturas sin avisar. En el aparato crítico no se indican las diferencias gráficas entre A y B.

\section{REGLAS DE LA MILICIA}

Capitulo primero: que cosa es hueste e commo cae por mengua de buena ordenança. Capitulo segundo: en que lugar se deue asentar la hueste.

Capitulo III: en que manera se deue asentar la hueste.

Capitulo IIII: commo se deue guarneçer e guardar la hueste des que asentada.

Capitulo V: que ha de faser la hueste des que asentada e los enemjgos paresçieren.

Capitulo VI: dela seguridad dela hueste.

Capitulo VII: dela proujsyon dela hueste.

Capitulo VIII: que ha de guardar la hueste quando se quisyere mober.

\section{FOLIO 64r}

Capitulo IX: en que manera deue pasar la hueste los rrios grandes.

Capitulo X: en que manera se deue ordenar la hueste quando esta aposentada.

Capitulo XI: que deue faser el que non tyene su hueste usada.

Capitulo XII: del ofiçio del adelantado del asentamiento dela hueste.

Capitulo XIII: que rrason mobio alos rromanos faser legiones.

Capitulo XIIII: quantas legiones leuauan los antiguos ala batalla.

Capitulo XV: en que manera se forma la legion.

Capitulo XVI: quantas cortes son en legion.

Capitulo XVII: delos nonbres e grandes delos prinçipes dela legion.

Capitulo XVIII: del ofiçio del mayor de la legion.

Capitulo XIX: del mayoral de los ferreros.

Capitulo XX: delos nonbres de aquellos que guyan las ordenes dela batalla.

Capitulo XXI: delos que procuran discordias e commo se ha de proueer.

Capitulo XXII: delas señales de caualleros.

Capitulo XXIII: quantas cosas son de consyderar para entender sy cumple pelear con çeladas o en otra manera.

Capitulo XXIIII: que cosas se deuen faser el dia dela batalla.

Capitulo XXV: commo el cabdillo deue saber delos caualleros que han de pelear que es lo que les pertenesçe.

Capitulo XXVI: commo se deue escoger el lugar para la pelea el buen cabdillo que quiere auer vitoria.

Capitulo XXVII: en que manera se deue ordenar la batalla por que non sea vençido. Capitulo XXVIII: quanto espaçio ha de auer de vn ombre a otro en luengo, e quanto de vna has a otra en ancho.

Capitulo XXIX: de las ayudas de las hases.

Capitulo XXX: los lugares de la batalla que deuen estar los cabdillos.

Capitulo XXXI: de los rremedios contra el poder e engaño delos enemjgos.

Capitulo XXXII: en quantas maneras se puede faser pelea e que cabtela se puede faser que los pocos vençan alos muchos.

Capitulo XXXIII: commo se deue dar lugar alos enemjgos que puedan fuyr. 
Capitulo XXXIIII: commo se deue aprestar la hueste quando non quiere pelear. Capitulo XXXV: que manera deue faser el prinçipe o cabdillo si fuye parte dela hueste o toda.

Capitulo XXXVI: delas reglas generales de las batallas.

\section{FOLIO 64v}

Prologo

Todas las cosas por vso e por costumbre se acresçientan e conseruan, asy pequeñas commo grandes, segund manifiesta mente por espiriençia paresçe. Et commo el arte de la caualleria e batallas sea mas noble que ninguna otra, la qual guarda e acreçienta la libertad e dignidades e onrras, et conserua las prouinçias e rreynos, ca por ella es todo conseruado, cada cosa en su estado. Por la qual, los antiguos dexaron todas las otras, non curando de aquellas punaron en guardar e saber sola mente aquesta, commo aquella por que se alcança onrra e vida e vitoria. E asy vsaron de aquella, trabajando e vsando por alcançar vitoria e onrra, que venieron a tanto que la pelea, que primera mente era en ventura, traxyeron arte e sabiduria e platica de aprender. E por que los despues de aquellos sopieren la dicha arte, aquellos escriujeron las cosas pasadas e los acaesçimientos delas batallas e el arte de aquellas, lo qual los buenos cabdillos sabios deuen faser, mandando e fasiendo a su gente vsar la manera de pelear por que puedan aprender e saber la dicha arte e ser maestros en aquella, syn la qual las otras non valen nin pueden faser, aujendo enxienplo en los romanos, los quales, aujendo grande deseo de alcançar onrra e vitoria de sus contrarios, escriuian e fisieron la dicha arte, e guardar e tener las ordenanças de aquella, por lo qual fueran señores de todos sus contrarios, ca non fallamos cosa que bastase los romanos subjudgar todo el mundo, salvo el grande vso de las armas e arte e sabiduria de asentar su hueste, e asy mesmo de pelear; otrosy por escoger cabdillo ardid e acuçioso e sufrido e sabidor e artero en pelear, e tal, que sepa e pueda enseñar el vso e arte de las armas e peleas, lo qual fase alos que lo saben ser osados e syn temor e de grande coraçon, que non hay atal que tema de faser lo que bien sabe, ca lo fase syn mjedo, por lo qual acaesçe muchas veses que los sabidores de la dicha arte e vsados en aquella, avn que sean pocos, vençer e auer vitoria dela gente ruda e non aujsada, en caso que sea mucha. Por lo qual, entre los romanos, era guardada tal costumbre que non dauan sueldo a cauallero fasta que, en presençia del capitan mayor de las legiones, mostrase commo lo meresçia, ca en todas cosas se puede emendar el yerro, mas los yerros delas batallas non se pueden reparar, que la pena viene en pos del yerro. Por ende, todos los que deste ofiçio quieren vsar con grande estudio

FOLIO 65r

e trabajo e alegre voluntad, se deuen disponer a vsar e aprender la dicha arte, lo qual saujendo, aujendo fiusia en el vençer delas batallas, seran dignos de alcançar onrra e vitoria, que es el fruto e galardon delos trabajos e afanes dela dicha arte; lo qual fasiendo, segund dicho es, en este mundo beujran en onrra e buena fama, e en el otro alcançaran gloria.

E commo declarar que cosa es hueste, se deua desir ante de todas cosas, diremos e mostraremos que cosa es aquella, e commo se deue de asentar e en que lugares, e guarneçer e basteçer e mober, por que sea mejor conseruada e guardada. Et dende en adelante proçederemos declarando las otras cosas necesarias e conplideras alo suso dicho.

Capitulo primero

Que cosa es hueste e commo cae por mengua de buena ordenança. 
Hueste es muchedumbre ayuntada de gente de cauallo e de pie, e asy lo dixieron los maestros delas armas. E sy los fechos leyeremos del rey Xerçes e de Dario e de Poro e de otros rreys que ayuntaron pueblos sin cuento, manyfiesta mente paresçera que las grandes huestes abastadas de muchas gentes, por mengua de buena ordenança, son muy ayna vençidas, mas por mengua de aquella que por fuerça e vertud delos enemigos. Asy mesmo la muchedumbre delas gentes por muchas maneras lo pasa peor, ca en los camjnos syenpre tardan mas e pueden resçeujr mayor engaño, asy en los lugares estrechos e asperos, commo en los pasos de los rios. Otrosy con grande trabajo pueden ayer viandas, ca es mala de auer la prouysion para la muchedumbre. E quando aquella, por mengua de ordenança, es vençida, peresçen muchos. Ende los antiguos, que aujan visto los peligros, non quisyeron auer hueste de grande numero de gente, ante, con grande examinaçion, trauajaron por auer omnes prouados en las armas en la hueste. E por quanto en las mayores batallas, ellos creyeron bastar vna legion con algunas ayudas, que eran dies mjll peones et dos mjll de cauallo. Pero sy los enemigos eran muchos, enbiauan vn grande conde con veynte mill peones et quatro mjll de cauallo, e fallauan ser mas prouechosas muchas huestes, que non grandes.

\section{FOLIO 65v}

Capitulo segundo

En que lugar se deue asentar la hueste.

La hueste se deue asentar en lugar seguro, e en tal, que aya abastamiento de leña e agua e viandas. E sy por luengo tiempo oujere de morar, escoja lugar sano e guarde que non asyente la hueste açerca de alguna altura, por que dende non le venga dapño. Iten se deue guardar el numero delos caualleros e fardajes, por que non se aprieten en lugar, sy fuere muchedumbre, e sy poca, non se estienda mucho.

\section{Capitulo terçero}

En que manera se deue asentar la hueste.

La hueste se deue asentar vnas veses en figura de quadratura, otra de triangulo, otra redonda, segund el lugar o la nesçesydad lo demandare. E la puerta prinçipal del rreal deue ser a oriente, e de cara los enemjgos. E sy la hueste andoujere camjno, deue ser la puerta fasia la parte do quisyeren yr.

Iten deue auer la hueste otra puerta, a la qual deuen estar las justiçias, por la qual deuen asacar a justiçias los que cometieren los malefiçios.

\section{Capitulo IIII}

Commo se deue guarnecer e guardar la hueste desque asentada.

El asentamiento de la hueste es en tres maneras. La primera, quando la nesçesydad, deuen de tajar çespedes e faser çerco enderredor dela hueste, que aya en alto tres pyes e que aya delante vna caua, que aya en alto quatro pies e en ancho seys. La segunda manera es sy los enemjgos fueren çerca. Conbiene que en la caua aya en alto nuebe pies, e en ancho dose con su estacada con la tierra que sacaren de la caua amontonada, e que aya la dicha estada ${ }^{62}$ en alto quatro pies. La terçera manera es que, sy la nesçesydad lo adebdare, la estacada deue ser fecha de resios maderos; la caua segund dicho es. Para las quales obras la hueste

FOLIO 66r

\footnotetext{
${ }^{62}$ estacada $\mathrm{B}$. 
deue traer açadones e palas de fierro e picos e los otros ynstrumentos para lo semejante nesçesario.

\section{Capitulo V}

Que ha de faser la hueste desque asentada e los anemjgos pareçieren.

Ligera cosa es de aperçebir e basteçer la hueste quando los enemjgos son absentes, mas quando son presentes, non es tan ligero de faser. Por lo qual es nesçesario que por pregon se sepa quales conplieron su obra, e los çentoriones vean las cauas, e aquellos que fueren fallados que non conplieron su obra, reçiban la pena estableçida, e cumplan las dichas cauas. Por lo qual faser, es nesçesario, sy los enemigos fueren presentes, segund dicho es, que la meytad dela gente delos de cauallo e de pie se pongan en la batalla a toda su mejoria a rrostro delos enemigos, por que las dichas cauas se puedan faser e acabar syn peligro. E toda la otra gente dela hueste que non fuere ocupada en las dichas cauas, este armada e aperçeuida segund que el caso requiere.

\section{Capitulo VI}

Dela sanidad dela hueste.

Sobre todo es de proueer que la hueste sea en sanidad, por lo qual se deue guardar de lugares en que aya pestilençia; eso mismo non deue morar çerca de lagunas nin de lugares secos syn arboles ${ }^{63}$ nin deuen estar los caualleros en el tiempo del estio syn tiendas, por que el enojamiento e calor del sol les faria grandes enfermedades.

Iten en la fortalesa del ynbierno, non deuen de andar camjno, nin estar en lugar donde aya mengua de agua, leña nin aguas malas, ca el beuer delas malas aguas engendra dolençias. Iten cada dia se deue faser pesquisa por los prinçipes e trebunos e el conde que ha mayor poder, commo pasan los enfermos, que sean proueydos.

Iten todos los dela hueste con grande estudio deuen ser enseñados, por que cada vno sepa el arte e vso delas armas con que han de pelear, ca la costumbre et vso de las armas lo puede saluar e dar vitoria.

\section{FOLIO 66v}

Capitulo VII

De la proujsyon dela hueste.

La rrason manda que digamos dela proujsyon, ca muchas veses se pierde la hueste antes por mengua de aquella que por pelea, que mas cruel es la fanbre que el fierro; que grande golpe e grande dardo es contra los enemjgos que tu ayas proujsyon e abasto, e ellos mengua. Por ende, todo rey o prinçipe, con grande cuydado, deue buscar las proujsyones por las comarcas con tiempo, e siempre en mayor copia que es mester. E sy por venta los trybutos de en prestido o de otra manera non bastaren, conbiene que faga las dichas proujsyones e se cunplan todas las cosas que son mester. Que posesiones nin bienes e requisas non pueden ser seguras, saluo sy son defendidas por armas; quanto mas, que muchas veses acaesçe por mengua dela dicha proujsyon doblar se la nesçesydad e mester, e la guerra durar mas.

Iten, todas las proujsyones que los enemigos podieren ocupar se deue con tiempo leuar alos logares seguros, lo qual non sola mente se deue faser por mandamiento, mas avn por premia.

Iten, ante que la nesçesydad venga, deuen ser repartidos e basteçidos, asy de proujsyones commo de ynstrumentos, para defender todos los lugares a que los

\footnotetext{
${ }^{63}$ Laguna en B.
} 
enemigos, en qual quier manera, puedan allegar, ca sy con tiempo non lo fasen podrian ser ocupados por los enemjgos, de que vernja muy grande dapño e quiça tal, que tarde o nunca seria reparado. Iten los omnes deuen ser escogidos para la batalla, e los que non fallaren tan aprouados, deuen ser enbiados e puestos en las fortalesas, que los que non aprouechan en las batallas, pueden aprouechar en defensyon de villa o de castillo; que vna de las mayores artes dela caualleria es conosçer a cada vno en que ofiçio puede mas aprouechar, por que aquello le sea mandado faser.

\section{Capitulo VIII}

Que ha de guardar la hueste quando se quesyere mober.

Commo sea verdad que muchos peligros suelen acaesçer ala hueste enlos camjnos, por lo qual el cabdillo o capitan deue proueer del remedio, por que, andando camjno, non aya de sofryr fortuna e, sy les venjere, sean aperçebidos alo resistyr e echar de sy. Para lo qual deuen escreuir ${ }^{64}$ complida mente todos los camjnos delas comarcas. E eso $^{65}$ mesmo deuen saber los lugares, e quanto ha de vno a otro, e los camjnos et senderos e atajos, lo qual deuen preguntar muy secreta mente a aquellos que lo saben. Iten, deuen auer guardadores fyeles que lo sepan faser, para que las carreras sean todas guardadas en manera que non pueda venir por ellas daño ala hueste.

Iten, deuen de guardar que non sepan los lugares e camjnos por donde ha de venjr la hueste, nin quando han de mober, ca por esto los antiguos oujeron señal de mobimiento e todo cabdillo deue enbiar omnes fyeles e ardydos con caualleros prouados, por que vean los lugares por donde ha de venir la hueste, asy delante commo detras, e ala parte diestra e synjestra, por que non pueda resçeuir daño por cabsa de sobreujenta. E esto se faga asy de noche commo de dia, lo qual fecho e ordenado, tomen el camjno primera mente los caualleros, e despues los peones, e los enbalajes e cargas e pertrechos e armas sean puestos en medio delos caualleros e peones, ca a los que van delante viene el peligro de frente, e a los de detras de espaldas. E alas costaneras deue estar egual gente de armas para enbargar las entradas, ca los que estan en las çeladas muchas veses encontran al traues. Por lo qual, ala parte que los enemjgos pueden venir, deuen ser puestos omnes de cauallo armados ligera mente, e esto mjsmo peones et vallesteros, e por que los enemjgos arrebatada mente non enpescan. E deuen ser amonestados los caualleros que sean aperçeujdos de coraçón e tengan las armas en las manos, porque las cosas prouadas e aperçeuidas non pueden ser espantosas nin dapñosas. Otrosy non deuen de yr apartados los vnos de los otros nin amontonados, mas en buena manera, que non se enbarguen los vnos alos otros. E eso mesmo deuen de ordenar çierta señal que aguarden el fardaje, por que vaya todo junto e non resçiua dapño nin enbargue a los que han de pelear. Eso mesmo deue de guardar el cabdillo los lugares en que han de pelear, que sy el tiene ventaja delos de cauallo, deue pelear en los canpos llanos e rasos, e sy delos peones, en los lugares estrechos et asperos; por lo qual deuen ser amonestados los tribunos o mariscales que detengan los delanteros, et acuçien los peresosos, ca los que mucho van delante, quando acaesçe alguna sobreujenta

FOLIO 67v

mas son prestos a foyr que tornar, e los que van detras ayna son vençidos. Otrosy todo cabdillo se deue guardar de las çeladas, que acaesçen algunas veses estar la çelada puesta e faser rebato manifiesto. Por lo qual, todo cabdillo deue de trabajar por

\footnotetext{
${ }^{64}$ laguna en B.

${ }^{65} l o \mathrm{~B}$.
} 
destruyr los lugares delas çeladas, por que aya conosçimiento de aquellas e, aquel aujdo, las puede engañar por aquella via e manera que el podia ser engañado.

Iten, todo prinçipe o cabdillo deue conoçer e saber la costumbre de sus enemjgos: sy acostumbraron cometer e venjr ellos cansados, camjnando de noche o ala mañana o quando; sy entran rreal para comer, e guardar se deue en aquellos tiempos.

Iten, deue el cabdillo saber sy tiene ventaja delos peones e delos omnes de cauallo o vallesteros, o por numero de omnes o por guarneçimiento de armas, asy que verdadera mente sepa lo provechoso a el e a sus enemjgos dapñoso.

Iten, deue el cabdillo saber sy le cumple andar de noche o de dia, e quantos son los lugares por donde han de yr, e quanto ha de vn lugar a otro, e que lugares son, por que se guarden del daño que les puede ser fecho, e de la mengua de agua en el estio, e dela sonbra delas njebes e frios en el ynbierno, en tal manera que la hueste non se falle engañada en el camjno e lugares por donde e adonde ha de yr.

\section{Capitulo IX}

En que manera deue pasar la hueste los rios grandes.

En el pasar de los rrios muchas veses acaesçe grande dapño a los que non son abisados. Por ende, quando acaesçiera que el agua sea mucha e resia, deuen de buscar el vado con los cauallos grandes e fuertes, e des que fallado, poner çiertos omnes de cauallo a riba e a yuso, por que los omnes e moços e fardaje e bestias flacas pasen por medio, que los que estan arriba quebrantan el agua que non venga tan resia, e los que estan abaxo, recogen a los que estan trastornados.

Iten, quando el agua fuere alta e non consyenta pasar se deue la hueste traer consygo barquetas anchas e tabladas aparejadas con clauos de fyerro, e tales pertrechos que se pueda faser puente syn tardança. Iten, por que en los tales lugares los enemjgos non fa

\section{FOLIO 68r}

gan daño, todo cabdillo deue ser aperçeujdo de poner gente de vna parte e de otra por defendimiento delos que pasan por el rio.

\section{Capitulo X}

En que manera se deue ordenar la hueste quando esta aposentada.

Cosa syn saber e llena de peligro es asentar la hueste syn proujsyon e basteçimiento, commo sea verdad que los caualleros derramados por buscar proujsyon ligera mente son engañados. Asy mesmo, la escoridad dela noche e la nesçesydad del sueño e el derramamiento delos caualleros son ocasyon de muchas sobreujentas et acaesçimjentos contrarios. Por lo qual, non basta el asentamiento dela hueste ser lugar bueno, mas que sea tal que otro mejor non se pueda fallar.

Iten, deuen de guardar que la hueste non sea asentada en tal lugar que tenga a çerca el agua mala, e a lexos, la buena.

Iten, que en ynbierno se asyente en tal lugar que non fallesca de mantenimjento nin leña, por que en los tiempos afortunados del ynbierno non se aya de mudar, e asy mesmo que non sea asentada en lugares asperos e apartados, nin çerca de monte alto e altura de otero. Iten, la hueste se deue asentar segund la nesçesydad del lugar conbiene, a saber, quadrada o redonda o luenga, pero la mas fermosa forma es que sea vn terçio mas luenga que non ancha.

Iten, las cauas que se fasen ala hueste es en tres maneras. La primera es por vna noche, la qual se ordena con çespedes e, sy los enemjgos estan çerca, deue ser la caua de çinco pjes en ancho et tres en alto; por sy la morada de la hueste fuere por algund tiempo, estonçe deuen faser las cauas con mayor cura e trabajo, e que aya en la caua, en ancho, dose pies, e en alto, ocho. E sy los enemjgos fueren mas poderosos, fagala 
de dies e ocho pies en ancho, e dose pies, en alto. E sea fecha con palancas fyncadas e rama texida, e los tribunos tomen cuydado de las mandar faser. E por que non aya algund rebato o sobreujenta delos enemjgos, çiertos de cauallo e peones delos que non fasen otra caua esten armados e aperçeujdos delante dela otra caua, e toda la noche velen e guarden, en manera que, por sobra de sueño nin peresa nin por mengua de discreçión e abisamiento, non sean engañados. E los

FOLIO 68v

tribunos tengan cargo delas velas e pongan quien ronde, por que vean las menguas dellas. Iten, los caualleros deuen poner sus guardas de dia fuera de lo çercado, e eso mesmo deuen guardar los pastos e lugares dela proujsyon, que le non puedan ser ocupados por enemjgos, que el enemjgo por mala voluntad va a lugar do entyende que ha de ser resystido.

\section{Capitulo XI}

Que deue faser el que non tiene su hueste vsada.

Todas las artes e obras vsando se acreçientan e non vsando se menguan. Quien dubda que la arte delas batallas non sea mejor que otras; por ${ }^{66}$ la qual la libertad es conserbada e la dignjdad acreçentada e las proujnçias del ynperio e reyno conservuadas; la qual es tan nesçesarya alos que han de pelear commo aquella por la qual cobran vida e alcançan vitoria. Por ende, abysado deue ser el cabdillo o prinçipe a quien tanto poderio es dado, e a cuya vertud son otorgadas tantas bien aventuranças commo por las vitorias se ganan, asy mesmo defendimiento de la tierra, salud delos caualleros, gloria del pueblo, que non tan sola mente aya cuydado de toda la hueste, mas de cada vno de aquella. E sy algund mal venjere ala hueste o a parte della por publica ynjuria, deue ser culpado, que la culpa es de aquel, porque tiene su hueste de moços e non vsada en armas. Por lo qual, con grande trabajo e diljgençia, deue costreñir aquella, por que sea vsada en las armas e sepa el arte delas batallas. Por ende, todos los de la dicha hueste deuen ser en el canpo muchas veses, ordenados e enseñados, segund el arte delas batallas, ordenando el has en luengo en manera que este derecha e non tenga senos o entornaduras, en tal guisa que cada vno este arredrado del otro segund deue. E despues el dicho cabdillo o prinçipe les deue mandar que apriesa e de resio doblen el has, en manera que, en aquella priesa grande, den la ordenança en el espaçio que primero tenia.

Iten, les deue mandar que breue mente e apriesa muden el has en manera de triangulo que es dicha has de turno, la qual fiso grande prouecho a muchos sabjos cabdillo en algunas batallas. Iten, les deue de mandar que fagan otra ves el has a manera de çerco, guardando cada vno su ordenança, por la qual guisa los caualleros bien vsados se suelen defender quando la fuerça delos enemjgos

FOLIO 69r

los apremja. E este remedio se fase por que, ronpida la has, non fuya la gente.

Iten, todo sabio cabdillo deue trabajar por conosçer todos los suyos, e sy pudiere ser, conosçerlos por nonbre, e qual es para mas o para menos.

Iten, quando los enemjgos andan seguros e derramados a robar, deue de enbiar quien les salteen e cometan, que cada que por algun caso o acaesçimiento los enemjgos sean vençidos con grande pabor e mjedo queda. E los que los vençen con esfuerço e voluntad de pelear, e avn a los otros dela hueste, creçe la osadia.

Iten, muy secreta mente deue ordenar los rrebatos e sobreujientas para los pasos de los rrios o desçendidas de los montes, e estrechuras delas syerras o grandes lagunas

\footnotetext{
${ }^{66}$ por, sobre la lin.
} 
e para los camjnos. Que vaya aparejado para cometer sus enemjgos, comjendo o dormjendo o estando de vagar o seguros o desarmados o en otra manera syn sospecha. Iten, sy los enemjgos venjeren de luengo camino, acometalos cansados e curen manera que cometa los postrimeros e alos que van descuydados, que las tales cosas son de tentar primero, porque, sy mal venjere, sea poco, e sy a bien se diere, aproveche mucho.

Iten, senbrar discordias entre los enemjgos obra es de sabio cabdillo, ca ninguna nación, avn que sea pequeña, dubda es poder ser conquistada por sus enemjgos sy ella misma por sus propias maldades non diere lugar a ellos, ca la mal querençia delos dela çibdad muy dapñosa es a su propia defensyon.

\section{Capitulo XII}

Del ofiçio del adelantado del asentamiento dela hueste.

Auja mayoral del aposentamiento e asentamiento de la hueste, e a este pertenesçia aposentar e ver la estacada e caua, e mandar faser las choças e casas de los caualleros e faser traer los enbargos. E por su mandado, se fasen las espensas destas cosas, e los carros e ynstrumentos en que trayan las viandas para la hueste, e las herramjentas para faser las cauas e estacadas e para conbatir e destruyr los muros, e vallestas e yngenios e todos los otros ynstrumentos que son menester en la guerra. E el qual era escogido entre los otros por abisado en armas, e mas sabio que los otros en la arte de la caualleria.

\section{FOLIO 69v}

Capitulo XIII

Que rrason movio a los rromanos faser legjones.

El nonbre de las legiones permanesçe fasta oy, mas por la grande negligençia delos presentes, creo que es quebrantada la fortalesa de aquellas e por la desordenada codibçia dela onrra, la qual non meresçen los que la quieren e ocupan los galardones a los que lo mereçen por sus obras e vertudes.

Iten, los ofiçios e onrras que syenpre fueron acostumbradas dar por trabajos e meresçimientos, dan se por graçia e favores a las personas non dignas de aquellas. Por la qual se amenguan las vitorias, ca las cosas que se fasen por antojo e voluntad son por algund tiempo, e las que se fasen por discreto consejo segund deuen, duran para syenpre.

\section{Capitulo XIIII}

Quantas legiones leuauan los antiguos ala batalla.

Fallase que los consoles romanos non leuauan alas batallas mas de dos legiones con sus ayudas contra muy poderosos enemjgos. E estos sabjan tanto en las armas e aujan tanta fiusia en aquellos que entendjan que, para vençer qual quier batalla por grande que fuese, bastauan aquellos. Onde es nesçesario que fynque con vitoria la tyerra, de la qual el señor de aquella e los suyos son sabidores de la arte de pelear e batallas.

Capitulo XV

En que manera se forma la legyon.

La legjon se forma e ayunta en quatro meses e los caualleros iuran por Dios e por Ihesu Xristo, su fijo, e por el Espirito Sancto, que guardaran, daran la fe e faran fe e lealtança al señor rey o prinçipe, e estaran por el bien comun de la tierra, e que noble mente e fiel faran las cosas que el rey o prinçipe les mandare, e que non desanpararan la caualleria nin fuyran ala muerte por defensyon dela tierra. 


\section{Capitulo XVI}

Quantas cortes son en legyon.

FOLIO 70r

En una legyon son dies cortes. En la primera corte tyene mjll e çiento e çinco peones, e çiento e treynta e dos omnes de cauallo enlorigados, e llamase corte millaria, e esta es la cabeça de la legion. Et quando ha de pelear, esta es la que comjença e tiene por señal una agujla. La segunda corte ha qujnientos e çinquenta e çinco peones, e sesenta e seys de cauallo, e llamanla corte quingentaria; la terçera corte, otros tantos, et la quarta corte, otros tantos. E la quinta tyene asy como la primera e ha se de poner en la syniestra ala, como la primera se pone en la diestra, e destas çinco cortes se pone en la primera has. La sesta corte ha quinientos e çinquenta peones, e sesenta e seys omnes de cauallo; la syete corte, otros tantos; la VIII corte, otros tantos; la IX corte, otros tantos; la desena corte, otros tantos. E destas dies cortes se fase vna legión en que ha seys mill e çiento peones, et syeteçientos e treynta et seys de cauallo. E non deue auer menos numero, antes algunas veses acostumbraron auer mayor. E esto es quando fasen todas las cortes yguales de la primera que es mjllaria.

\section{Capitulo XVII}

Delos nonbres e grandes delos prinçipes de la legion.

Segund las nomjnas e matriculas, el tribuno mayor es nonbrado por cura del rey o del prinçipe, que lo fase capitan mayor, e el tribuno menor es prinçipal delos caualleros de su linaje. Los ordinarios son llamados aquellos que gujan las ordenes de los que han de pelear e los ordena. Enperiales llaman alos que por mando del enperador o prinçipe son ayuntados a los ordinarios que ordenan la batalla. Alferçe disen por los que lieuan los pendones. Otros llaman deseados, por que han cura delos enfermos, e son deseados de aquellos. Otros llaman mensajeros, por quanto van por mandado del cabdillo et fasen mober la hueste.

\section{Capitulo XVIII}

Del ofiçio del mayor de la legyon.

En estas legjones enbjauan syempre algunos delos consoles de Rroma, a los quales obedesçian todas las legiones enla ordenança dela

FOLIO 70v

pas o dela guerra o delas peleas. E estos consoles dexauan alas veses en su lugar otros nobles caualleros por mayores, que llamauan prefetos, los quales rregian e mandauan, e tenjan cada vno poder asy commo vicario del consolo. E todos sabjan su mandamiento. E este ponja las velas e las guardas e fasia obedeçer a todos enlas cosas que conplian faser. E sy algund cauallero fasia alguna cosa que non deujese, el tribuno le daua la pena por mandado deste prefecto. E so cura deste estauan las cosas que pertenesçian a los caualleros, asy commo armaduras, vestiduras e bestias e viandas, e a el pertenesçia castigar e corregir los males que se fasian. E por su mandado se trabajauan todos los vsos de la caualleria e armas, asy peones commo caualleros, e el se trauajaua de ser justo, cuerdo, mesurado, aperçeujdo en todas las cosas, e enformaua la legjon en toda bondad e ardides e caualleria, ca çierto es que los subditos sabjdos, buenos e vertuosos grande onrra es del señor.

\section{Capitulo XIX}

Del mayoral delos ferreros.

En la legion auja ferreros, carpenteros, panderos e todos los otros ofiçios que nesçesarios eran para faser lo ala guerra nesçesario, asy choças commo engenjos, carretas, escudos, lorigas, capellinas, dardos, arcos, vallestas, pasadores e todas las 
otras maneras de armas que eran conplideras para conbatyr e defender e pelear en canpo; para las quales cosas auja vn mayoral cuyo cuydado era sobre esto, en gujsa que non fallesçiese cosa que fuese nesçesaria.

\section{Capitulo XX}

Delos nonbres de aquellos que gujan las ordenes dela batalla.

El primer prinçipe de la legjon fue dicho çenturion porque regia quatro çenturias en la has primera. El segundo prinçipe guiaba dos çenturias e llamaban le dosenturio. E otro prinçipe regia media çenturia, e este ordenaba todas las cosas que aujan de faser en la legyon. Otro regia çenturia e media, e otro regia vna çenturia en esta manera: regyan çinco ordenadores dies çenturias, e para estos ordenadores ordenaron FOLIO $71 \mathrm{r}$

los antiguos grandes prouechosos ${ }^{67}$ de grande onrra, por que los otros caualleros trabajasen de alcançar los dichos ofiçios.

Iten, auja otros çenturiones que regyan çiertas çenturias, e otros que llamauan decuriones, que regian cada vno dies caualleros. La segunda corte dela primera has auja çinco çenturiones, e asy mesmo, cada vna delas otras fasta la deçima has, asy que auja en toda la legion çinquenta e çinco çenturiones.

\section{Capitulo XXI}

De los que procuran descordias e commo se ha de proueer.

Algunas veses los de la hueste mueben e procuran ruydos e discordias; los quales lo fasen a fyn de non pelear, e fasen lo aquellos que son acostumbrados de beujr oçiosa mente, e son dados a juego de dados, e comer e beuer desordenada mente, e non son acostumbrados del asperesa e trabajo de las armas, e quanto es forçado sofryr aquellos que por ellas quieren beujr e ser onrrados. E por mjedo, temjendo la batalla, son osados mober discordias entre los de la hueste. Por lo qual, todo cabdillo o capitan, sabia mente, deue trabajar por conosçer aquellos e amonestar los que se curen dello. Iten, deuen ser los tales mobedores de discordia por los tribunos vicarios, a quien es dado el poder, apremiados ${ }^{68}$, con grande rygor de justicia, se ensañen e ensayen en las armas e en el vso de aquellas, por que estos atales mas saben en mirar las armas que non en menearse nin pelear con ellas. Por lo qual, deuen ser traydos por muchos dias e con grande vso faser todas las cosas que conbjenen ala pelea, e desque asy fueren vsados, podran ser aujdos por caualleros, por que cobdiçiaran mas la pelea que beujr oçiosos e desordenada mente e jamas non curaran dela discordia nin de ruydo. Que todo aquel que en su arte o fuerça tyene con fiusia, menos preçia los ruydos e discordias, e todo prinçipe o cabdyllo deue ser diligente e acuçioso en saber sy ha en la hueste los tales armadores de discordia e pelea o revoltosos, e con cordura e sabio consejo deue apartar a los tales dela hueste e enviar los en guardas delas villas o castillos, e en tal manera lo deuen faser que, quando los desecha, paresca que los escoje. Pero sy nesçesario fuere melesina del cochillo, fagase iustiçia, por que todos ajan mjedo e pocos la pena, pero mas de loar son los prinçipes e cabdillos que por su trabajo e discreçion los traen por bien que por mal.

FOLIO 71v

Capitulo XXII

De las señales de caualleros.

$$
\begin{aligned}
& { }^{67} \text { pertrechos } \mathrm{B} . \\
& { }^{68} \mathrm{e} \mathrm{B} \text {. }
\end{aligned}
$$


Muchas cosas son de desir e amonestar alos que han de pelear que guarden e fagan, ca, quando la contienda es sobre la onrra e vida non deue ser la mengua dela diligençia perdonada, ca non ha cosa para que el omne tan ayna pueda alcançar vitoria, commo es obedesçer e complir los mandamientos e señales delos mayores. Que las señales fueron falladas por que en las peleas non pueden regyr los cabdillos por palabra sola mente, saluo por las señales, las quales la hueste deue de entender e conoçer por que sepan e conoscan lo que han de faser.

\section{Capitulo XXIII}

Quantas cosas son de consyderar por entender sy cumple pelear con çeladas o en otra manera.

Todo aquel que quiere la obra delos delanteros del arte dela batalla sacada breue mente delos auctores de aquella, primera mente deue oyr la rason dela pelea e las rreglas e mandamjentos de aquella. Pelea publica es cosa que se acaba en dos o en tres oras, e la parte vençida pyerde toda esperança, por lo qual todo cabdillo deue pensar primera mente todas las cosas antes que vengan a la pelea, ca los buenos cabdillos tarde o nunca asyentan pelear en publica pelea o batalla, antes cometen escondida mente, por que sean vençedores con menos peligro e daño, e por que puedan mas ayna vençer sus enemjgos e faser les mayor daño.

Iten, grande arte e prouecho es al cabdyllo escoger de toda la hueste omnes que sepan de batalla e sabios e aujsados en pelear. Con aquellos deue tratar muchas veses del poderio de los suyos e delos enemjgos, non dando lugar a lisonja en qual quier tratamjento. Deue saber e conoscer de entre sy e sus enemjgos: qual tyene mas o menos sabjos de pelear e qual mas armados e mas vsados de batalla, e quales tyene mejores caualleros. Asi mesmo deue saber quien tyene mejores vallesteros e mejores omnes de pie. E segund los que toujeren auantaja de su enemjgo, asy acometa la pelea.

Iten, deue de saber qual de las partes tyene mayor proujsion e mantenimjento. E otrosy todo buen cabdillo deue saber sy le combiene pelear luego o alongar la pelea, ca muchas veses quando se ljeua a la luenga enflaquece el aduersario, o por mengua o por voluntad e deseo delos suyos se torna a su tierra.

Iten, non podiendo faser cosa alguna, acaesçe yr se por desesperacion, por lo qual algunos lo desamparan e avn acaesce faser le traicion, que en las cosas contrarias rrala es la fe e fyr

FOLIO 72r

mesa.

Iten, al fecho de la obra pertenesçe saber quales aduersario o sus cabdillos e gentes sy son soberbios o atentados o osados o temerosos sabidores de arte de pelear o non; sy son fuertes o flacos e que coraçones han e en qual parte se promete mas vitoria $\mathrm{e}$ galardones, ca non con semejantes cosas se acrecienta la virtud para la pelea e por mengua de aquella se quebranta.

Iten, deue el cabdillo trabajar que venga a los aduersa rios cosas contrarias, asy como cometiendo a los que fallare derramados o mal caualgando, que toda cosa contraria que venga alos adversarios da grande esfuerço a la vna parte e quebranta mucho a la otra. Iten, deue el cabdillo catar su gente sy ha sydo en guerras luengo tiempo o poco, o sy han veujdo luenga mente en pas, ca por menos caualleros son aujdos los que han veujdo en pas que en guerra, por lo qual el cauallero deue faser vsar a los suyos las armas, por que pueda alcançar el arte de pelear e sepan en que manera deuen estar aparejados e obedecer alos mandamientos de aquellos que les dieren cabdillos e las señales del mayor e sus mandamientos e voluntades. E sy erraren en algunas cosas destas, fagan gelas vsar e enseñar fasta que lo sepan. 
Iten, el cabdillo deue ser tenprado en comer e en beuer e sabio en lo que ha de faser con consejo delos suyos.

Iten, deue ser abysado en conosçer entre su aduersario e el qual tyene mas abantaja. E sy fallare tener la el, non dexe de cometer la combenjble pelea, e donde toujere abantaja su adversario, deue se guardar e deue vsar de rebatos e de sobrebjentas e de çeladas, ca muchas veses acaesçio por aquesto vençer los pocos alos muchos e auer la vitoria.

\section{Capitulo XXIIII}

Que cosas se deuen faser el dia dela batalla.

La razon nos convida ala arte dela caualleria, commo sea verdad que toda batalla la vitoria de la qual esta en un acaesçimjento, el qual tiempo se espera grande gloria alos acuciosos e ardidos, e grande peligro e dapño alos necios e perezosos e negligentes, en qual tiempo e vso de la sabjduria e arte e consejo de pelear se aseñorean.

Iten, en los tiempos antiguos auja en costumbre leuar alas batallas caualleros acostumbrados a poca vianda, por que fuesen mas osados quando comjesen algund tanto mas, e sy la

FOLIO $72 \mathrm{v}$

pelea mucho durase, sofriesen el trauajo e non cansasen por mengua de non comer. Iten, quando el cabdillo acaesçiese estar en algund lugar e sus enemjgos lo venieren a buscar, non deue sacar su gente del lugar o moradas do estoujesen, que en quanto la gente salen pocos a pocos, los enemjgos que estan juntos e prestos pueden faser daño en los tuyos. Por lo qual, deues proveer que tus caualleros salgan fuera e aparejen su has antes que los enemjgos vengan, e sy acaesçiese que los enemjgos vengan aperçeujdos estando los tuyos dentro en la çibdad, entonçe tarda la salida para quando los enemjgos dexaren de combatyr, e aquellos, que ellos pensaua que non saldrian, esten folgados e prestos. Que quando los adversarios bolujeren desordenados e cansados, salgan los tuyos dela çibdad alegres e folgados e den ellos. E para mjentes que non te aguixes nin lieues los cauallos ${ }^{69}$ a todo correr, ca el cauallo que ha de pelear por el correr pierde el fuelgo, pues ¿que fara aquel que non tyene aliento? Que desigual condiçión es pelear el folgado con el cansado. Mas regiendo bien los tuyos e esforçando los, acomete los enemjgos con la mayor abantaja que podieres e dura mente, e Dios medjante, alcançaras vitoria.

\section{Capitulo XXV}

Commo el cabdillo deue saber delos caualleros que han de pelear que es lo que les pertenesçe.

Quando los tus caualleros han de pelear esto escodriña con todo tu saber: que les pertenesçe e la fiusia e espanto e miedo, sy vieres en la cara e palabras e andar e mobjmjentos.

Iten, non te afiuses por el mancebo codiciar la pelea, ca dulce es la pelea del que non la ha prouado.

Iten, asy abiene alongar la batalla, sy los que son vsados e prouados en ella temen la pelea, do vertud de coraçon creçe ala hueste sy el cabdillo los esfuerça e amonesta que fagan su deuer, mayor mente sy han alguna rason e esperança de auer vitoria.

Iten, en tal tiempo deues notificar a los tuyos del yerro e la mengua delos enemjgos, por que seles mueban los coraçones con todo odio e yra contra ellos.

\footnotetext{
${ }^{69}$ caballero B.
} 
Iten, antes que pelees conbiene que ordenes muchas veses tu hueste en lugares seguros, ca las cosas que son vsadas non las temen tanto.

\section{FOLIO 73r}

Capitulo XXVI

Commo se deue escoger el lugar para la pelea e el buen cabdillo que quiere auer vitoria.

El buen cabdillo que quiere auer vitoria conbiene conosçer el lugar donde oujere de pelear, por que pueda tomar la mejoria de aquel, el qual, tanto es mas provechoso quanto fuere mas alto, que los dardos mas rresios desienden que suben, e el que contiende en el otero entra en dos peleas. Iten, sy tu esperas que por los peones vençeras, deues escoger lugares asperos e de montes, e sy con los de cauallo entiendes auer vitoria, deues escoger lugares llanos, syn montes e lagunas.

\section{Capitulo XXVII}

En que manera se deue ordenar la batalla por que non sea vençido.

Todo aquel que ha de ordenar batalla deue de catar el viento e el sol, por que el sol, quando da de cara quita la vista, e el viento la enbarga e trae poluo a los ojos. Por ende, en tal manera se deue ordenar la batalla que el viento e el sol le den en las espaldas, sy ser podiere o alo menos non de cara. Ley de establesimjento es que en la primera orden sean puestos los caualleros vsados de armas, e en la segunda, los caualleros e otros omnes con lanças e dardos. E cada vno dellos armados acostumbrauan non ocupar tres pies, en guisa que en mjll pasos se ordenan mjll e seysçientos e sesenta e seys peones en luengo, en manera que la has non se treslusca ${ }^{70}$ et aya espaçio de se trabar las armas entre orden e orden. Alas espaldas quisieron que oujiese en ancho seys pies, por que los peleadores ouiesen espaçio de llegar e de tornar. Estas dos ordenes han de ser armados de armaduras mas pesadas por quanto estan en lugar de muro, los quales non deuen ser apremjados que se acerquen nin sygan en pos delos contrarios, por que non se desordenen, ca estos han de resçeuir a los que fuyeren e faser los tornar contra los enemjgos, e estando quedos e peleando. La terçera orden se conpone de vallesteros mançebos e omnes de pie con armaduras ligeras.

Iten, la quarta orden se fase de omnes escudados delos mas mançebos e vallesteros desenbueltos e fonderos, e estos con armadura liujana.

Iten las primeras dos

FOLIO $73 \mathrm{v}$

ordenes deuen estar quedas, commo es dicho, commo muro. E la terçera e quarta orden deuen saljr a pelear lançando dardos e viratones ${ }^{71}$, e sy estas vençieren alos enemjgos, ellos e los de cauallos persygan los, e sy los enemjgos los fisieren boluer, tornen se ala primera e segunda orden, las quales sostienen la batalla fasta venjr alas espadas.

Iten, en la quarta has se pongan los que lançan piedras con hondas fuertes, o con fondas de seda o de ljno.

\section{Capitulo XXVIII}

Quanto espaçio ha de auer de vn omne a otro en luengo, e quanto de vna has a otra en ancho.

\footnotetext{
${ }^{70}$ Laguna en B.

${ }^{71}$ Los viratones son saetas de ballesta cuya rotación al ser lanzados era muy dañina.
} 
Declarado es en que manera se deuen ordenar las hases, enla qual ordenança se contiene que mjll pasos se ocupan con mjll e seys çientos e sesenta e seys peones, porque cada vno ocupa tres pies; asy que para seys hases en mjll pasos de canpo es menestar nuebe mjll e nuebe çientos e nobenta e seys peones, e seys pies de ancho de vna has a otra; asy que dies mjll peones ordenados en seys hases auera quarenta e dos pies en ancho e mjll pies en luengo. E sy la quisieras adelgazar el doblo torna en ancho de veynte e vn pies, e en luengo, dos. E segund este cuento e medida se quiera, sean veynte o treynta mjll, se podra ligera mente ordenar tanto que sepa el cabdillo que lugar es e quantos armados podra caber. Pero sy el lugar fuere estrecho e los armados abastaren, en tal caso, poder se han ordenar dies hases o mas, segund fuere la gente, que mas seguro es pelear estando allegados que armados. E sy la has fuere muy delgada ayna se puede romper, e sy esto ujere, arredrada non sera tan ayna acorrida.

\section{Capitulo XXIX}

Delas ayudas delas hases.

Mucho ayna ha la vitoria que el cabdillo tenga aparejados detras de sus hases omnes escogidos, asy de pie commo de cauallo, asy en los cabos commo en la meytad, con buenos capitanes sabios e aujsados e syn temor, los quales han de estar FOLIO $74 \mathrm{r}$

sobre saljentes, por que en qualquier lugar que los enemjgos fisieron daño, estos lleguen e cumplan la mengua delos que falleçieren, poniendo esfuerço alos suyos, quebrantando la osadia delos enemjgos, que por esto los rromanos vençieron muchas batallas.

Iten, sy quisieres faser cuño o tigera o has de syerra o peña, faselo delos sobejanos, que sy tu quisyeres sacar el cauallero donde lo as puesto, toda la orden turbaras. E toda via sey abysado que tengas mitat en las espaldas, que sy la has o tropel delos enemjgos fisiere daño o ronpymjento en qualquier parte de tu batalla, las ayudas sobredichas acuçia ${ }^{72}$ pongan remedio.

\section{CAPITULO XXX}

Los lugares de la batalla que deuen estar los cabdillos.

El cabdillo mayor deue estar ala parte derecha entre los omnes de cauallo e los peones, ca este es el lugar donde se gobierna toda la has e en que esta todo el acorrimjento. E por ende deue ser el cabdillo puesto en tal lugar, por que con seso e obra pueda regyr asy los de cauallo commo los de pie. E deue tener consigo muchos de cauallo e de pie sueltos por que, sy nesçesario fuere, ataque el cabo synjestro de los aduersarios e les pueda feryr por las espaldas. El segundo cabdillo se deue poner en la meytad del has delos peones, por que los sostenga e esfuerçe. E este deue tener peones delos sobejanos, muy fuertes e bien armados, para que faga dellos cuño para ronper el has delos enemjgos. E sy los aduersarios fisieren cuño, faga el tijera que los pueda contrastar.

Iten, en la syniestra parte deue estar el terçero cabdillo, sabio e esforçado, porque la parte syniestra es la mas floja. E este deue tener delos sobejanos buenos omnes de cauallo e peones ligeros, para que puedan la parte syniestra estender, por que non sea çercado de los enemjgos.

\footnotetext{
${ }^{72}$ con gran acuçia $\mathrm{B}$.
} 
Iten, las boses delos que pelean non se deuen alçar antes que las hases se ayunten, ca a los neçios e de poco saber pertenesçe dar boses de alueñe, mas quando junta mente los colpes llegan en vno, acaesçe poner espanto en los enemjgos.

Iten, deues estudiar en las cosas que asy sean prouechosas e al aduersario dañosas, e deues acrecentar la

FOLIO 74v

osadia a los tuyos con fiusia de galardones, lo qual es esperança de vitoria.

Iten, deues trabajar por cometer antes que seas cometido e ser aperçeujdo de ocupar e començar la cosa ante que tu aduersario.

\section{Capítulo XXXI}

De los remedios contra el poder e engaño delos enemigos.

Dicho auemos commo la pelea es contraria alos que vienen cansados por los camjnos, e alos que fincan en los pasos delos rrios, e alos empachados con las grandes aguas, e a los que trabajan en pasar puertos o montes o oteros, e alos que andan en los canpos derramados e seguros, e alos que duermen en el alojamiento, a los quales todos suelen venjr sobrebjentas e enojamientos arrebatados e muy dañosos. Por lo qual, el cabdillo sabio e abisado syenpre deue ser aperçeujdo e estar todos tiempos a buen recabdo que, quando los dela hueste se ocupan en juegos o en otros negocios que sean contrarios ala guarda e buen recabdo, antes son muertos e deshonrados que se puedan ordenar nin perçebir nin faser cosa que les preste para su defensyon.

Iten, en caso que de cometer supita mente, acaesçe muchas veses los pocos vençer alos muchos, pero donde non ay manera que se pueda faser, conbiene pelear por ygual condiçion, que la arte delas batallas non ayuda menos a los enseñados en pelea publica que en los engaños escondidos o ençelados.

Iten, mucho deues de guardar que los tuyos non sean çercados de muchedumbre de enemjgos por la parte syniestra, lo qual muchas veses acaeçe, o por la parte diestra, en caso que a pocos acontesçe, o de tropeles grandes delos enemjgos. Por lo qual acaesçiendo, el remedio es que fagas redonda la tu ala syniestra o diestra, qualquier que fuere tentada, por que los tuyos bueluan e defiendan las espaldas de sus compañas, e en el rincon de aquella parte sean puestos omnes fuertes e esforçados, por que ally se suele faser mayor arremetida.

Iten, el cuño deue ser de peones que vayan juntos con la has, e va primero angosto e despues mas ancho, e ronpe las ordenes delos aduersarios lançando muchos dardos en vn lugar, alo qual suelen llamar los caualleros que saben el arte "cabeça de puerco"; contra el qual cuño

FOLIO $75 \mathrm{r}$

a cabeça de puerto se ordena la tigera, la qual se fase de muy escogydos caualleros, puestos en manera de tigera e resçiuen en sy aquel cuño e çercan lo de cada parte. Iten, la has de syerra es ordenada de los escogidos, la qual se pone ante la frente delos enemjgos, por que se repare la has que estoujere turbada. Tropel es llamado que, apartados de la su has, se van contra los enemjgos con sobre vienta o rrebato, contra el qual es menestar otro tropel mas poblado de gente e mas fuerte.

Iten, deuedes guardar que, en el tiempo que se comete la batalla, non se mueban las ordenes de las gentes nin los caualleros nin peones saljendo a otras partes, ca desto nasçeria confusyon e roydos, e la gente turbada de ligero es vençida.

\section{Capitulo XXXII}

En quantas maneras se puede faser pelea publica e que cabtela se puede faser que los pocos vençan alos muchos. 
Syete son las maneras de pelear. La vna es quando la hueste se ordena quadrada e con luenga frente, mas los sabios en armas non la han por buena nin prouechosa, porque se estyende en luengo espaçio, e non se falla toda via canpo ygual para ella, e fase se en el canpo alguna abertura o seno o retuerta, por lo qual acaesçe muchas veses romper se la batalla. E demas desto, el aduersario puede venjr por delante o por las costaneras o cerca dela ala diestra o syniestra, en que es grande peligro; por lo qual, sy non tyene omnes sobejanos para resystyr e contrastar alos enemjgos, pueden ende resçeujr grande daño. En esta manera peleando, el que tenia muchos, peleara solo. La segunda manera de pelea publica es, quando las hases ordenadas se vienen ayuntar, apartaras tu ala siniestra alueñe dela diestra del aduersario, e la tu ala diestra, la qual ternas bien ordenada, juntaras con la syniestra del tu enemjgo, e por ally començaras la pelea, de guisa que la çerques, e asy çercada, vengas alas espaldas delos enemjgos. Et sy por ally començares arromar tus enemjgos, veras vitoria e la FOLIO 75v

tu ala syniestra que estoujere arredrada de tu enemjgo, durara segura.

La terçera manera de pelear es semejable ala segunda e avn que es contraria, por que enpieça a pelear el ala syniestra con la diestra de los enemjgos, que manjfiesta mente cometen grande peligro los que pelean dela ala synjestra, pero sy acaesçiere que tu tengas la tu ala synjestra mucho mejor e demas fuertes caualleros e peones que la diestra, en tal caso allega la tu ala synjestra ala diestra ala del enemjgo, a la qual sabes que tyenes los peores batalladores, por que non la acometan nin alleguen a ella. E en esta gujsa pelearas prouechosa mente, tenjendo tu aduersario la su ala diestra floia, e tu, la tu syniestra resia. La quarta manera es quando ordenares la tu batalla antes quatroçientos o qujnientos pasos que venga a tu enemigo, non esperando lo, te conbieje mober luego anbas las alas, por que de cada parte fagas fuyr tus enemjgos, mas esta manera de pelea, maguera ayna venças, sy el troxiere los omnes vsados en armas puede ser peligrosa, por que es forçado de espojar e desnudar la mediana parte de su has al que asy pelea, e partyr su hueste en dos partes, e sy el enemjgo non fuere vençido en el primero golpe e falle las tus alas partidas, la mediana has desamparada, puede resçeujr grande daño.

La quinta manera es semejable a la quarta, pero ay diferençia en quanto pone ante la primera has vallesteros, por que con su esfuerço de aquellos non se pueda el has rromper, ca asy commo con su ala diestra comete la synjestra del enemjgo e con la su synjestra a la diestra de aquel, sy alguno puede faser fuyr, luego los vençe trabajando la primera has que esta delantera con armadura ligera e vallesteros.

La sesta manera es quando la has ordenada se llega alos enemjgos. Tu allega la tu ala diestra a la synjestra de aquellos e comjença la batalla con caualleros prouados ${ }^{73} \mathrm{e}$ peones ligeros, e la otra parte de la tu ${ }^{74}$ hueste, apartala mucho del tu enemjgo e tiendela en derecho commo espeto ${ }^{75}$, que quando començares a sobyr ${ }^{76}$ a la su ala syniestra e a las espaldas, sin dubda le fagas fuyr e el aduersario non

FOLIO 76r

puede acorrer a los suyos nin de la parte diestra nin de la has mediana, e por que la tu has se estiende a semejança del espeto, por que se apartan delos enemjgos.

\footnotetext{
${ }^{73}$ privados B.

${ }^{74}$ Sobre la lín.

${ }^{75}$ espexo $\mathrm{B}$.

${ }^{76}$ Laguna en B.
} 
La septima manera es que sy toujeres pocos e menos fuertes, cates lugar de mejoria, para que te puedas defender de tu enemjgo. Sy toujeres altura o otero o mar o rrio o lagunas o monte o abreturas o lugar aspero, en una parte del qual el enemjgo non puede llegar, asy ordena la otra toda tu hueste en has derecha, mas en aquella ala que esta guarnimjento por todos los omnes de cauallo e las vanderas. E asy pelearas seguro con tu enemjgo, que dela vna parte la natura del lugar te defendera, e de la otra parte, se pone doblada caualleria. Que sy quisyeres de la tu ala synjestra pelear, ally pone $^{77}$ los mas fuertes, e sy de la diestra eso mesmo, e sy en medio quisyeres faser cuños con que rompas la has de los enmjgos, cata que el tal cuño ordenaras de omnes muy vsados en armas, ca muchas veses acaesçio los pocos alcançar vitoria, seyendo ordenados e puestos en lugares que la razon manda.

\section{Capitulo XXXIII}

Commo se deue dar lugar alos enemjgos que puedan fuyr.

Los que non saben los fechos delas batallas e caualleria, cuydan que es vitoria çercar los enemjgos en tal manera que non puedan fuyr, a los quales acaesçe con desesperaçion creçer les osadia. Por ende es de loar a aquel que sabe aparejar el camjno delos enemjgos por do fuyan quando fallan lugar abierto. Los coraçones consienten boluer las espaldas, delo qual a los vençedores non viene peligro, commo los vençidos ayan bueltas las armas con que se aujan de defender. E non se deue de faser cuenta dela muchedumbre de aquellos delos quales el corazon es espantado.

\section{Capitulo XXXIIII}

Commo se deue apartar la hueste quando non quiere pelear.

Los sabios dela arte de batallas disen commo todo prinçipe o cabdillo, quando vea que non le cumple pelear, deue ser aujsado e con grande maestria saber se apartar delos enemjgos, non por que se aparte en la tal manera que amengue

FOLIO $76 \mathrm{v}$

el esfuerço a los suyos e a los enemjgos acreciente osadia. Para lo qual ha de tener tal manera que los suyos non entiendan que va por fuyr, mas que piensen e crean que por alguna arte torna atras, para que el enemjgo se aluergue a otro lugar en que mas ligera mente sea vençido, o por que las çeladas se pongan mas seguras. E avn a muchos acaesçio poner los de cauallo ante los peones, por que sus enemjgos non viesen a los peones quando se fuesen.

Iten, otros entresacauan delas primeras hases llamando los atras, e les quedauan en su orden. E aquellos pocos a pocos ayuntan los con los otros que aujan llamado atras. E primero algunos se yuan con la hueste de noche, por algunos camjnos que buscauan, por que los enemjgos, veyendo el dia, entendiesen que non podyan tomar alos que yban delante.

Iten, alos que yban ligera mente armados enbiauan los a las alturas, para que ally fuese la tornada de la hueste mas segura. E sy los enemjgos los quisiesen segujr, los que estauan armados ligera mente e con los cauallos que estauan primera mente en el lugar, persygan los. E muy peligrosa cosa es quando los que estauan en la çelada salen de rrostro a los que van nesçia mente en el alcançe. E este es el tiempo en que las çeladas e las asechanças mejor se puedan poner, por quanto a los enemjgos del fuydo creçe la osadia con menor cura, e nesçesaria mente la seguridad puede padesçer e auer mayor peligro.

\footnotetext{
${ }^{77}$ asy por $\mathrm{B}$.
} 
Iten, las sobrebientas e males suelen venir sobre los que estan mas destruidos e non se temen de mal, commo a los que comen e beuen cansados del camjno, e a los que dan a paçer a sus cauallos e a los que non han sospecha de cosa ninguna tal; en las quales ocasiones combiene mucho a todo prinçipe o cabdillo de se guardar e trabajar por enpeçer asus enemjgos, ca este es vn caso que, a los que mal pasan, non les puede aprouechar muchedumbre nin grande poder nin la fuerça, ca el que en publica pelea es vençido puede acusar a la fortuna, mas el que padesçe por la manera suso dicha, non puede escusar su culpa e grande nesçedad e peresa, por qual se podia bien guardar o por otras muchas maneras.

Iten, ay otras muchas maneras de çeladas, conbiene a saber: quando algunos de cauallo siguen el alcançe e la fuerte gente enviala ascondida mente por los lugares, e quando son venidos los de cauallo a los enemjgos, tyenta la lebjana mente e van se. E los enemjgos piensan que todas las asechanças son pasadas, e asy el non pensar se torna en mengua e negligençia e estonçe la gente que era

FOLIO 77r

enbjada, sobre viene e vençe alos neçios.

Iten, sy han de yr por montes, deuen de enviar adelante omnes que tomen los lugares asperos, por que non padescan asechanças e se guarden de çeladas.

Iten, tajar arboles e çerrar en pos de sy los camjnos, lo qual se llama encadenar, por quitar a los aduersarios el poder delos perseguir.

Iten, pocos mas o menos, a cada parte que tenga sabio cabdillo e gente bien mandada es commo la ocasyon, ca el que va adelante puede bien echar çeladas en valles conbenibles e montes espesos, e dexar en pos de sy las dichas asechanças e çeladas. E quando en ellas cayere el enemjgo, tornara en ayuda delos suyos.

Iten, el que siguen por los contrarios senderos, mucho ante enbie omnes sueltos, e quando va el aduersario remuebe le el paso delos rrios e destruye a los que primero pasaren. E los que vienen detras alleguen quanto puedan e destruyan e dañen alos que non han pasado.

\section{Capitulo XXXV}

Que manera deue faser el principe o cabdillo, sy fuyo parte de la hueste o toda.

Es de saber que sy alguna parte dela hueste quedare e alguna parte fuyere, non deuemos por eso desesperar, ca en tal nesçesydad, la firmesa e confiança del cabdillo puede alcançar la vitoria, ca syn cuento acaesçio esto. E son aujdos por mas altos de coraçon e esfuerço los que en este caso non desampararon, ca por fuerte deue ser tenjdo aquel al qual non quebrantan las cosas contrarias. E este deue tomar primero los espojos delos enemjgos vençidos. E por esto, disen: coja el canpo aquel que por su fermesa e esfuerço se alegro con los clamores dela batalla e espanto a los enemjgos e doblo la fuerça e esfuerço delos suyos, commo sy de toda parte fuese vençedor. Mas, sy por algund caso, toda la hueste fuere a destruyçion, es la tal cosa, pero avn non fallecio la forma dela reparaçion, para lo qual es demandar melesina e remedio. El cabdillo sabio, con tal cabtela deue pelear en publica batalla, que sy alguna cosa acaesçiere por la aduersydad ${ }^{78} \mathrm{o}$ desuario delas batallas o dela condiçión de los omnes, quel libre los vençidos syn grande daño; ca sy estan çerca

FOLIO 77v

algunos collados o oteros, sy alas espaldas tenja guarnicion e sy, todo lo al fallecido ${ }^{79}$, algunos muy fuertes estoujeron e pelearon e ellos guardaron a sy e a los suyos; ca

\footnotetext{
${ }^{78}$ deuilidat $\mathrm{B}$.

${ }^{79}$ fallesçiendo $\mathrm{B}$.
} 
muchas veses, la guerra vençida, torno en sy mismo e vencio alos que le segujan, ca nunca mayor desbarato nin tan grande puede venir a los que estan alegres, commo quando subita mente la su fortalesa se les torna en espanto e pabor. E mas, en qual quier cosa que sea, son de recoger los que quedaren dela batalla e levantarlos con amonestamjentos convenibles, rreparando los con armas. E estonçe, los buenos buscan nuebas ayudas, e lo que mas les aprouecha es cometer los mismos vençedores por ascondidas asechanças. E sy la osadia es de reparar, catese oportunjdad para ello e non fallesca, ca las voluntades delos omnes de ligero se leuantan a soberuja. Sy algo pensare en este postrimero caso, pare mjentes alos fuydos de todas las batallas, que los mas son contra aquellos que aujan de ser vençedores.

\section{Capitulo XXXVI}

De las reglas generales delas batallas.

I.- La primera condición delas batallas es que, aquellas $\operatorname{cosas}^{80}$ que a ty aprouechan, dañan al aduersario. E lo que a el ayuda, a ty estorua. Por eso non deuemos faser cosa segund su volunta.

II.- Iten, el que mas velare e mas trabajare en el canpo e usare sus caualleros en las armas, menos peligro avera en la batalla, ca non es de leuar cauallero en la batalla que primero non ayas prouado.

III.- Mejor es domar el enemjgo con sobrebientas e rrebatos e espantos que con pelea publica, en la qual la fortuna puede auer mayor poder que la vertud del tu poder. IIII.- Non ha mejores consejos que el aduersario non saber lo que tu quieres faser en la batalla.

V.- Mas suele ayudar la manera que poder nin fuerça.

VI.- El resçeujr los enemjgos, sy con fe se vienen a ty, grande fiusia es, ca mucho quebranta al aduersario los que se parten del o lo dexan.

VII.- Mejor es guardar mucho defendimiento detras de la has que derramar ni lançar la caualleria.

VIII.- Malo es de vençer el que verdadera mente judga el su poder e el delos enemjgos.

VIIII.- Mas ayuda la fuerça e el saber que la muchedumbre.

X.- Muchas veses ayuda mas el lugar que el poder.

XI.- La natura pocos varones crea fuertes, mas la buena enseñança a muchos fase ardidos.

XII.- La hueste con el trabajo crece, e con el vagar se

FOLIO 78r

mengua.

XIII.- Non lieues cauallero a publica pelea que non aya esperança de vitoria.

XIIII.- Las obras arrebatadas espantan los enemjgos, las vsadas se envileçen.

$\mathrm{XV}$.- El que los suyos tyene derramados e nesçia mente persigue alos enemjgos, dar quiere al aduersario la vitoria.

XVI.- El que non se apercibe para dar alos suyos las cosas nesçesarias, syn fierro sera vencido.

XVII.- Quando la esculca anda ascondida mente en la hueste, todos deuen ser tornados a sus çenturias por un dia e breue mente sera tomada.

XVIII.- Sy sopieres que tu consejo es reuelado a tus aduersarios, combiene te mudar el ardid.

\footnotetext{
${ }^{80}$ Añadido sobre la línea. 
XIX.- Lo que se deujere faser, trata lo con muchos, mas lo que oujeres concluydo con pocos e fieles.

XX.- A los caualleros, el temor e la pena los castiga enla pas, mas enla guerra, esperança e galardones los fase obedientes e leales.

XXI.- Los buenos cabdillos tarde o nunca pelean en batalla publica, saluo por ocasyon o nesçesydad. Mas conbiene vençer al enemigo por fanbre que por farto.

XXII.- Asconde de tus enemjgos la manera en que has de pelear, por que te non pongan contrarios remedios.

Fecha de recepción del artículo: noviembre 2005.

Fecha de aceptación y versión final: febrero 2006. 